\author{
UNIVERSIDADE DE SÃO PAULO \\ ESCOLA DE ENGENHARIA DE SÃO CARLOS \\ DEPARTAMENTO DE ENGENHARIA ELÉTRICA
}

\title{
ANÁLISE DE REDES ÓPTICAS SEM COMUTAÇÃO USANDO O MÉTODO DO TRÁFEGO ALEATÓRIO EQUIVALENTE
}

\author{
José Augusto Ferraz de Campos \\ Dissertação apresentada à Escola de Engenharia \\ de São Carlos da Universidade de São Paulo \\ como parte dos requisitos para obtenção do título \\ de Mestre em Engenharia Elétrica
}

Orientador: Prof. Dr. Amílcar Careli César

São Carlos, SP

Julho de 2002 
Dedico esta dissertação à minha esposa Maria Lúcia e aos meus filhos Ulisses e Gustavo pelo amor, apoio e incentivo que me concederam durante todos estes anos. 


\section{AGRADECIMENTOS}

A Deus, pela saúde e paz que desfrutei durante todo o tempo de execução deste trabalho. A Ele pertencerá toda a honra e toda a glória que provier desta obra.

Ao Professor Doutor Amílcar Careli César pela orientação, dedicação, amizade, apoio e incentivo durante todo o decorrer deste trabalho.

Aos professores Murilo Araújo Romero e Ben-Hur Viana Borges por terem participado da banca de qualificação, colaborando com importantes sugestões.

Aos docentes deste departamento pela amizade e conhecimentos transmitidos.

Aos colegas dos cursos de mestrado e doutorado do Grupo de Telecomunicações deste departamento pela amizade e incentivo.

Aos funcionários deste departamento pelo apoio e disposição em bem servir.

Aos funcionários das bibliotecas da Escola de Engenharia, Instituto de Ciências Matemáticas e de Computação e Instituto de Física de São Carlos da Universidade de São Paulo pela disposição no atendimento.

A todos que contribuíram direta ou indiretamente para a concretização deste trabalho. 


\section{ÍNDICE}

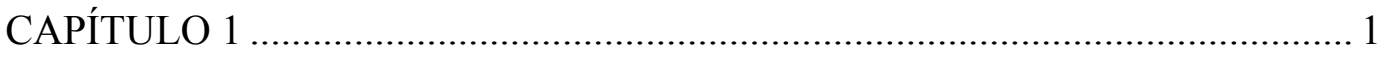

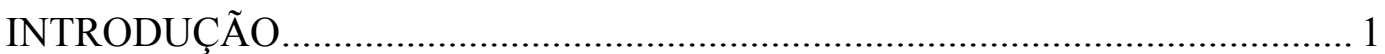

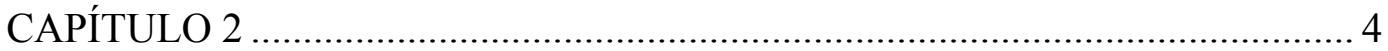

ESTRUTURA DE UMA REDE ÓPTICA SEM COMUTAÇÃO .......................... 4

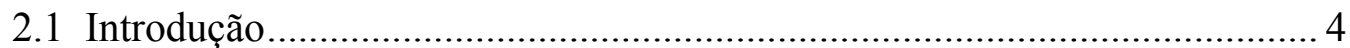

2.2 Estrutura da rede sem comutação .............................................................. 5

2.3 Estrutura da seqüência de conversores de comprimentos de

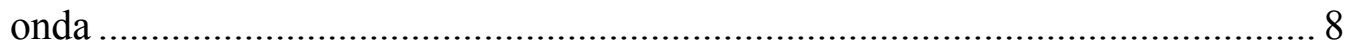

2.4 Roteador de rede com guias de onda (WGR - waveguide

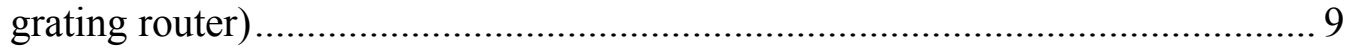

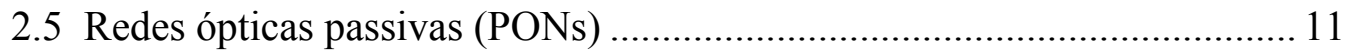

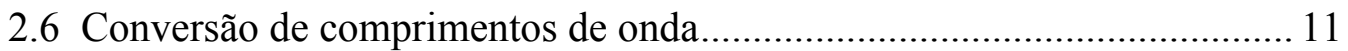

2.7 Transmissores sintonizáveis .............................................................. 14

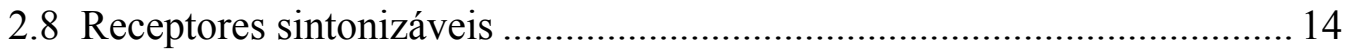

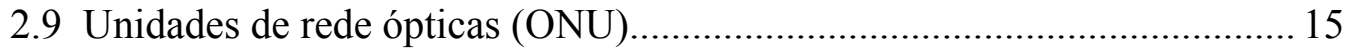

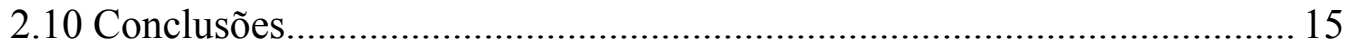

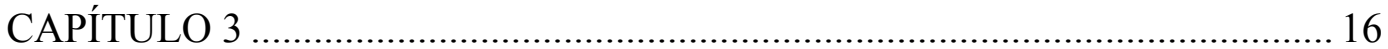

TRÁFEGO EM SISTEMAS DE TELECOMUNICAÇÕES ............................... 16

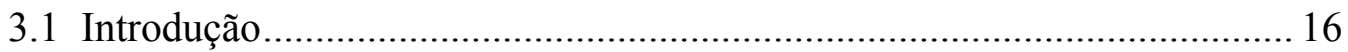

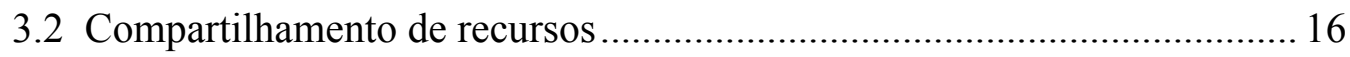

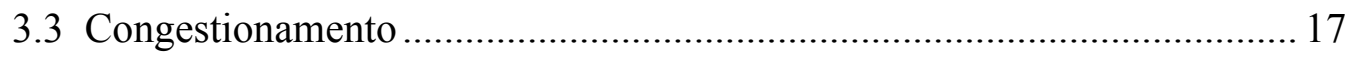

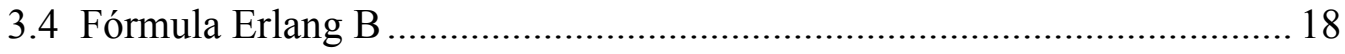

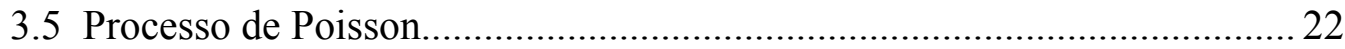

3.6 Extravasamento de tráfego de um grupo primário de recursos ............. 22

3.7 Extravasamento de tráfego de um conjunto de vários grupos primários

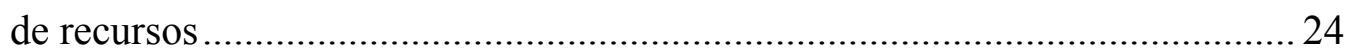

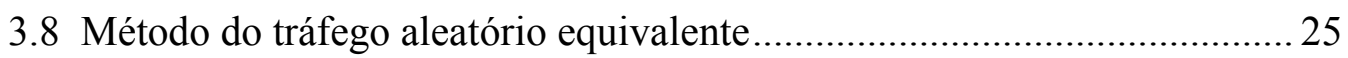

3.9 Solução aproximada de Rapp .............................................................. 28

3.10 Fórmula de aproximação de Hayward........................................................ 29 


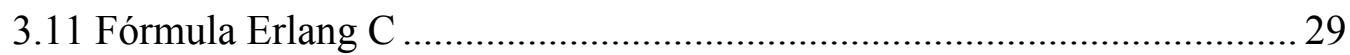

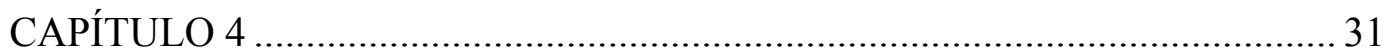

MODELAGEM ANALÍTICA PARA O DIMENSIONAMENTO DE REDE

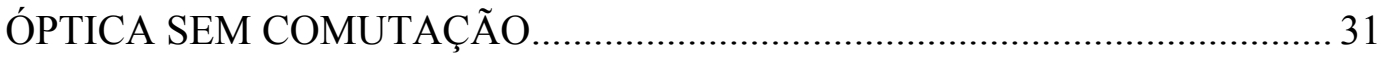

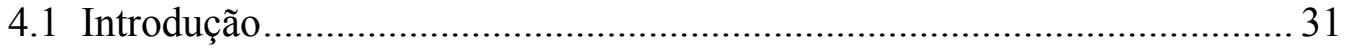

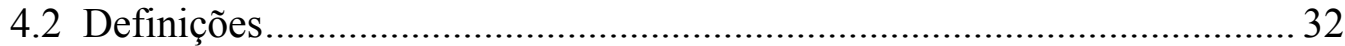

4.3 Cálculo da probabilidade de bloqueio no sistema de recursos primários e

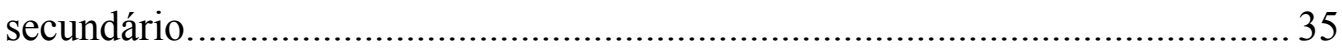

4.4 Relação entre os parâmetros de um grupo primário de recursos......... 40

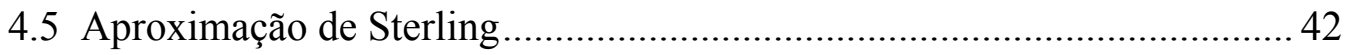

4.6 Considerações sobre o tráfego da internet.................................................. 42

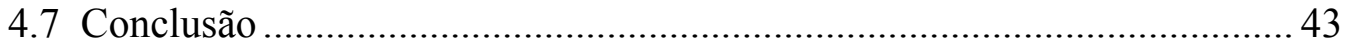

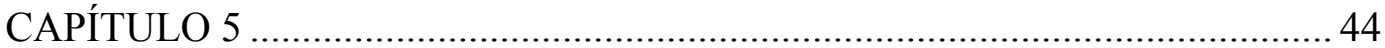

RESULTADOS DO DIMENSIONAMENTO DA REDE ................................. 44

5.1 Introdução

5.2 Relação entre o número de PONs e o número de slots de tempo nos

comprimentos de onda pertinentes às portas da PWRN

5.3 Cálculo da probabilidade de bloqueio de uma rede óptica sem comutação em função do número de portas reservas 48

5.4. Probabilidade de bloqueio em função do número de portas reservas e do

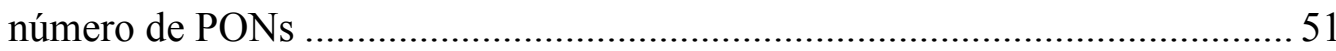

5.5. Probabilidade de bloqueio em função do número de slots de tempo .....

5.6. Número máximo de clientes que pode ser atendido por uma rede óptica sem comutação em função do número de portas reservas................55

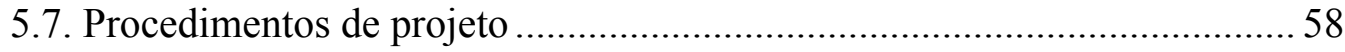

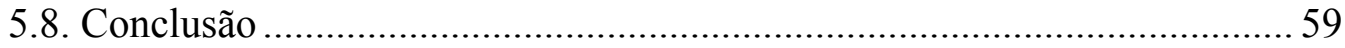

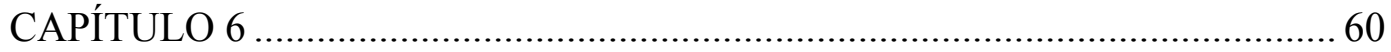

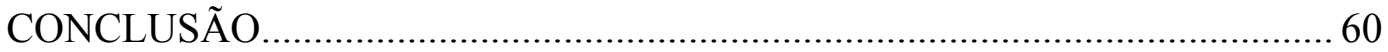

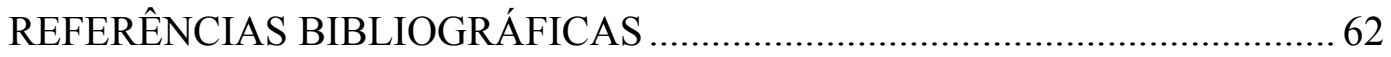

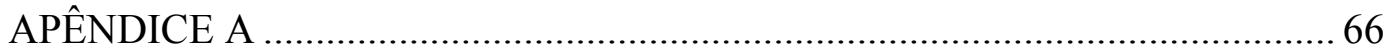

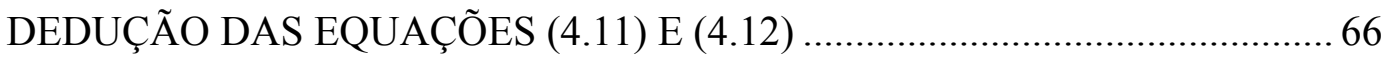




\section{LISTA DE FIGURAS}

Figura 2.1 Estrutura de uma rede óptica sem comutação............................... 6

Figura 2.2 Exemplo de alocação sem conflito de comprimentos de onda,

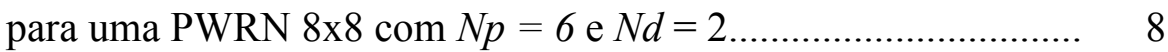

Figura 2.3 Estrutura de uma seqüência de conversores de comprimentos de

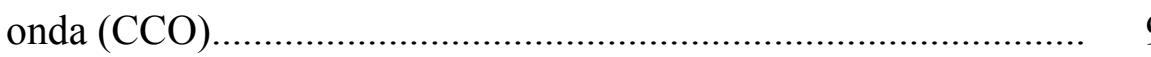

Figura 2.4 Roteador de rede com guias de onda (WGR)...............................

Figura 2.5 Uma típica estrutura de dispositivo amplificador óptico em semicondutor

Figura 2.6 Conversor de comprimentos de onda SOA por modulação de ganho cruzado: (a) Princípio de operação [12]; (b) Característica da saturação de ganho [15].

Figura 3.1 Modelo de extravasamento simples.

Figura 3.2 Grupos primários de recursos equivalentes [25].

Figura 4.1 Conexões entre PONs. Um comprimento de onda dedicado à conexão direta entre duas PONs está representado em vermelho. Uma conexão entre duas PONs através de uma porta reserva utiliza uma seqüência de dois comprimentos de onda, representados em azul e verde.

Figura 4.2 Esquema do fluxo de tráfego numa rede óptica sem comutação...

Figura 5.1 Número de PONs, $N p$, versus número de slots de tempo, $T$, nos comprimentos de onda pertinentes às portas da PWRN para diversos valores de carga de tráfego oferecida ao sistema.............

Figura 5.2 Número de PONs, $N p$, versus número de slots de tempo, $T$, , nos comprimentos de onda pertinentes às portas da PWRN para os cenários de tráfego Cs1 a Cs6 especificados na Tabela 5.1

Figura 5.3 Gráfico da probabilidade de bloqueio em função do número de portas reservas. Adotados $N p=10, A o=30$ erl e $T=20$.

Figura 5.4 Faixa de variação da curva da probabilidade de bloqueio versus número de portas reservas, entre os limites determinados por 
dois valores de $A o$ (30 e 32 erl). Foram adotados $N p=10$ e $T=$ 20

Figura 5.5 Probabilidade de bloqueio em função do número de portas reservas e do número de PONs. Considerou-se região residencial média (150000 clientes, carga oferecida de 7500 erl). O número de slots de tempo foi fixado em 50 ......

Figura 5.6 Número de portas reservas, $N d$, versus número de PONs, $N p$. Foram adotados $\mathrm{Ag}=7500$ erl e $T=50$.

Figura 5.7 Probabilidade de bloqueio em função do número de slots de tempo de cada comprimento de onda. Foi considerada uma região residencial média com 150000 clientes $(A g=7500$ erl $)$. Foi fixado $N d=1$

Figura 5.8 Número máximo de clientes que pode ser atendido por uma rede óptica sem comutação em função do número de portas reservas para $P<10^{-2}$. Foi considerado um cenário de tráfego em que os clientes são exclusivamente comerciais. Foi fixado $N p=10 \ldots \ldots .$.

Figura 5.9 Número máximo de clientes que pode ser atendido por uma rede óptica sem comutação em função do número de portas reservas para $P<10^{-2}$. Considerou-se um cenário de tráfego em que os clientes são exclusivamente comerciais. Foi fixado $T=30$. 


\section{LISTA DE TABELAS}

Tabela 5.1 Cenários de tráfego................................................................... 47

Tabela 5.2 Número de PONs necessárias em cada cenário. Foi fixado $T=$

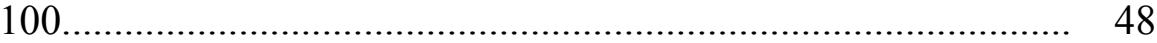

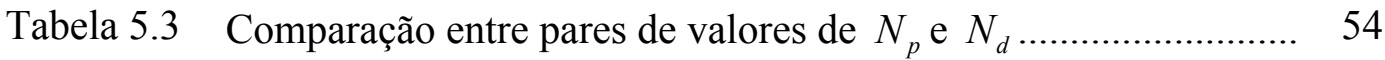




\section{LISTA DE SIGLAS E ABREVIATURAS}

$\begin{array}{ll}\text { ANATEL } & \text { - Agência Nacional de Telecomunicações } \\ \text { ATM } & \text { - Asynchronous Transfer Mode } \\ \text { DWDM } & \text { - Dense Wavelength Division Multiplexing } \\ \text { MEMS } & \text { - Micro-Electrical-Mechanical System } \\ \text { OADM } & \text { - Optical Add/Drop Multiplexer } \\ \text { ONU } & \text { - Optical Network Unit } \\ \text { OXC } & \text { - Optical Cross Connect } \\ \text { PON } & \text { - Passive Optical Network } \\ \text { PWRN } & \text { - Passive Wavelength Router Node } \\ \text { SOA } & \text { - Semicondutor Optical Amplifier } \\ \text { TDMA } & \text { - Time Division Multiple Access } \\ \text { TELESP } & - \text { Telecomunicações de São Paulo S/A } \\ \text { WDM } & - \text { Wavelength Division Multiplexing } \\ \text { WDMA } & - \text { Wavelength Division Multiple Access } \\ \text { WGR } & - \text { Wavelength Grating Router }\end{array}$




\section{LISTA DE SÍMBOLOS}

a = carga oferecida

$A_{0}=$ carga oferecida em uma PON de entrada em direção a uma única PON de destino

$A_{0 t o t}=$ carga oferecida em todas as PONs de entrada em direção a uma única PON de destino

$A_{c 1} \quad=$ média relativa à parte da carga oferecida que é transportada por um comprimento de onda que conecta diretamente uma PON de entrada com uma PON de destino

$A_{c 2}=$ média relativa à carga que é transportada através das portas reservas

$A_{0 R} \quad=$ média relativa ao fluxo de extravasamento de um comprimento de onda que conecta diretamente uma PON de entrada com uma determinada PON de saída (PON de destino), e que é a seguir oferecido às portas reservas

$A_{R} \quad=$ média relativa ao fluxo de extravasamento do sistema

$A_{p} \quad=$ somatória das médias relativas aos fluxos de extravasamento dos comprimentos de onda que conectam diretamente $\left(N_{p}-1\right)$ PONs de entrada à uma mesma PON de destino e que são a seguir oferecidos às portas reservas

$\alpha=$ variância relativa à carga que é rejeitada pelo grupo primário de recursos

$B(\mathrm{~s}, a) \quad=$ fórmula Erlang $\mathrm{B}$

$c \quad=$ fator de granulosidade

$C(s, a)=$ fórmula Erlang $\mathrm{C}$

$E_{j} \quad=$ estado de um sistema quando o número de clientes que o utilizam é $j$

$\lambda \quad=$ taxa de chegada de chamadas

$N \quad=$ conjunto dos números naturais

$N_{d} \quad=$ número de portas reservas 
$N_{p} \quad=$ número de PONs

$N_{\text {tot }} \quad=$ número total de usuários

$P \quad=$ probabilidade de bloqueio de todo o sistema

$P_{1} \quad=$ probabilidade de que uma chamada originada na i-ésima PON de entrada com direção à j-ésima PON de saída não seja acomodada em nenhum dos $T$ canais TDM

$\Pi=$ probabilidade de bloqueio no sistema de recursos primário e secundário experimentada pelo tráfego oferecido ao sistema

$\Pi_{c} \quad=$ probabilidade de bloqueio no grupo secundário experimentada pelo tráfego que extravasa dos grupos primários

$\tau=$ tempo médio em que uma chamada ocupa um tronco

$V_{0} \quad=$ variância relativa ao fluxo de extravasamento de um comprimento de onda que conecta diretamente uma PON de entrada com uma determinada PON de destino 


\section{RESUMO}

O objetivo deste trabalho é utilizar o método do tráfego aleatório equivalente para analisar e dimensionar redes ópticas sem comutação para arquitetura de nível único. Uma modelagem analítica, baseada nesse método, que possibilita otimizar os parâmetros da rede considerando padrões mínimos de desempenho é descrita.

A rede em estudo utiliza apenas um nó, onde se realizam as funções de roteamento passivo. Em anexo ao nó existem seqüências de conversores de comprimentos de onda gerenciados por um controlador de rede. A estrutura da rede consiste de um certo número de redes ópticas passivas (PONs) conectadas às portas do nó. Essas PONs são distribuídas pela área geográfica onde estão os clientes a serem atendidos. O acesso ao meio constituído pelas PONs é disciplinado por meio da utilização de um esquema WDMA / TDMA administrado pelo controlador de rede. Os comprimentos de onda pertinentes a cada PON conectada a uma porta de entrada do nó são alocados de tal forma que cada um deles se direciona a uma diferente porta de saída e, por conseguinte, a uma diferente PON de destino. Uma conexão entre dois terminais é estabelecida pela seleção de um intervalo de tempo (slot de tempo) pertinente ao comprimento de onda que conecta suas respectivas PONs através do nó. Caso esse comprimento de onda já esteja com sua capacidade plenamente utilizada, conexões adicionais podem ser estabelecidas utilizando-se um comprimento de onda direcionado a uma seqüência de conversores de comprimentos de onda anexa ao nó. Após a conversão, é utilizado outro comprimento de onda que é direcionado pelo nó à PON de destino.

A modelagem analítica investigada é utilizada para obter as relações entre os parâmetros da rede, possibilitando a escolha dos seus melhores valores.

Palavras-chave: redes ópticas sem comutação, dimensionamento de redes, método do tráfego aleatório equivalente. 


\section{ABSTRACT}

The purpose of this work is to use the equivalent random traffic method for analysis and dimensioning of switchless optical networks for single-layer architecture. This work reports an analytical model that allows the network dimensioning according to some relevant design parameters and the required system performance.

The analyzed network is based on a single node providing passive routing functions. Wavelength converter arrays, controlled by a network controller, are added in the node. The network structure consists of a set of passive optical networks (PONs) connected to the node ports. Those PONs are distributed along the geographical area where the customers to be assisted are. The access to the medium constituted by the PONs is disciplined through the use of a WDMA / TDMA scheme administered by the network controller. The pertinent wavelengths to each PON connected to an input port of the node are allocated in such a way that each one is addressed to a different output port and, consequently, to a different destination PON. A connection between two terminals is set up by the selection of a time slot pertinent to the wavelength that connects its respective PONs through the node. If the capacity of the wavelength is fully used, additional connections can be established by the use of wavelength directed to a wavelength converter array enclosed to the node. After the conversion, another wavelength addressed by the node to the destination PON is used.

The connections achieved between the network parameters are detailed to allow the choice of the best network parameters.

Keywords: switchless optical networks, network dimensioning, equivalent random traffic method. 


\section{CAPÍTULO 1}

\section{INTRODUÇÃO}

A instalação e manutenção de um sistema de comunicação via cabos ópticos, cuja finalidade é atender clientes distribuídos em uma área geográfica, geralmente envolve custos elevados. Sua implantação ou ampliação exige um tempo relativamente longo. Pela sua abrangência e capilaridade em ruas e estradas fica bastante sujeito a danos e defeitos. Por outro lado, as empresas de telecomunicações precisam manter um equilíbrio entre a qualidade do serviço oferecido ao cliente, serviço esse que também é monitorado pelas agências reguladoras governamentais, e o custo do mesmo devido à forte concorrência existente. Diante disso, percebe-se que é de extrema importância projetar esse sistema de comunicação com a melhor configuração possível.

Assim, métodos precisos de análise e dimensionamento de redes ópticas adquirem fundamental importância para os projetos vindouros, tanto quanto as estruturas totalmente ópticas que estão sendo propostas atualmente.

Os sistemas de comunicação ópticos estão passando por uma evolução onde, entre outras modificações, se procura eliminar o gargalo eletrônico. O grande crescimento do tráfego provocou maior exploração da enorme largura de banda das redes com fibra óptica, que foi bastante ampliada com os avanços da tecnologia DWDM. Por outro lado, houve um crescimento relativamente lento na velocidade de processamento eletrônico, o que significa que dados transmitidos opticamente precisam ter sua velocidade reduzida em cada nó se o mesmo é comutado eletronicamente. Pretende-se então encontrar caminhos para a próxima geração da infraestrutura da informação, que possa transportar pacotes diretamente na camada óptica sem qualquer conversão opto-eletrônica-óptica (O/E/O). Busca-se desenvolver um novo paradigma onde não sejam necessárias memórias dinâmicas (buffer) na camada WDM, até porque ainda não existem dispositivos ópticos para esta finalidade (para memória óptica só existem linhas de retardo feitas de fibra). Procura-se também diminuir camadas, uma vez que algumas delas existem apenas por razões históricas [1]. 
A tecnologia WDM tem avançado com a crescente melhoria do desempenho de multiplexadores/demultiplexadores WDM, multiplexadores add/drop ópticos programáveis (OADMs), crossconects ópticos (OXCs) e outros componentes [2]. Atualmente estão sendo apresentados crossconects totalmente ópticos usando a tecnologia de sistemas micro-eletromecânicos (MEMS) [1], [2], nos quais a configuração de uma trajetória óptica dura um intervalo de tempo da ordem de milissegundos.

Os avanços em dispositivos de comunicações ópticas, bem como em fibras ópticas tendem a tornar a largura de banda maior e mais barata. Poderia então ser considerado o uso de circuitos ponto a ponto bidirecionais comutados mesmo para sessões interativas. Aplicações como pesquisar na Web poderiam ser consideradas para circuitos ponto a ponto. $\mathrm{O}$ tráfego seria em rajadas, o que significa que os circuitos seriam usados de forma ineficiente, mas os atrasos seriam bem menores que em uma sessão bidirecional estabelecida através de redes de comutação de pacotes [2].

Por outro lado, as interfaces de serviço estão ficando mais rápidas (fast Ethernet, Gigabit Ethernet e 10 Gigabit Ethernet). Sinais de serviços de gigabits por segundo ou mais podem ser lançados, de maneira econômica, diretamente nos comprimentos de onda ópticos. Neste cenário, o papel da hierarquia digital síncrona (SDH) e da rede óptica síncrona (SONET) deverá ser reduzido, e a rede de transporte óptica poderá prover diretamente uma estrutura de transporte global [3], [4].

Nesta evolução dos sistemas de comunicações ópticos, uma das propostas em estudo consiste de uma plataforma de rede de nível único para conexões ópticas ponto a ponto, habilitada para atender a um grande número de terminais em uma vasta área geográfica [5]-[7]. Tal estrutura, denominada rede óptica sem comutação, é baseada em apenas um nó que executa funções de roteamento passivo [8]-[11]. Esse nó atua também controlando ativamente a conversão de comprimentos de onda em um sistema secundário de recursos, utilizado quando as conexões primárias necessárias estiverem ocupadas [12]-[16]. Nessa rede é utilizado um esquema WDMA / TDMA (Wavelength Division Multiple Access / Time Division Multiple Access) [5]-[7]. Um terminal é conectado ao nó roteador 
passivo por intermédio de um conjunto de comprimentos de onda. Em cada comprimento de onda o tempo é dividido em uma seqüência de intervalos distintos (slots). Essa seqüência de slots de tempo é repetida indefinidamente. Uma conexão entre dois terminais é estabelecida pela seleção de um slot de tempo pertinente ao comprimento de onda que é roteado através do nó passivo entre os dois terminais. O termo "sem comutação" é usado pelo fato de não haver necessidade de comutação eletrônica nessa rede, tampouco de cross-connects ópticos, a não ser para o nó roteador de comprimentos de onda [7].

Para tal estrutura, é fundamental que existam modelos analíticos confiáveis para permitir o correto dimensionamento de seus parâmetros.

Neste trabalho é descrita a modelagem analítica para o dimensionamento das redes sem comutação para arquitetura óptica de nível único com o objetivo de otimizar os seus parâmetros, para diminuir custos, considerando padrões mínimos de desempenho.

Essa análise será feita considerando-se apenas a existência de tráfego telefônico, com a intenção de demonstrar a capacidade do sistema e a investigação dos principais resultados relacionados ao dimensionamento do sistema.

Este trabalho está organizado da seguinte maneira. A descrição da rede óptica sem comutação está apresentada no Capítulo 2. A teoria de tráfego em sistemas de telecomunicações é apresentada no Capítulo 3. A modelagem desenvolvida para aplicação na rede em estudo é apresentada no Capítulo 4. Por meio dessa modelagem são obtidos resultados que são relatados e discutidos no Capítulo 5. 


\section{CAPÍTULO 2}

\section{ESTRUTURA DE UMA REDE ÓPTICA SEM COMUTAÇÃO}

\subsection{Introdução}

Um dos objetivos da proposta de redes opticas sem comutação é a simplificação da estrutura de rede pela utilização de apenas um nó, onde se realizam as funções de roteamento passivo, bem como a conversão de comprimentos de onda controlada por um controlador de rede pertencente ao nó. Por meio da eliminação da necessidade de nós complexos dentro da rede, esta abordagem não convencional pretende oferecer uma solução efetiva e viável para a realização de redes totalmente ópticas de alta capacidade, habilitadas a atender ao aumento de tráfego previsto relacionado aos novos serviços de telecomunicações.

Estudos relativos a esse modelo de rede projetam que, obtendo-se uma redução tanto no ruído introduzido pelo nó roteador, como nas não-linearidades das fibras, será possível conseguir transmitir 400 comprimentos de onda a 2,5 Gbits/s em uma única fibra em distância superiores a $1000 \mathrm{~km}$ [6]. Com um número suficientemente grande de comprimentos de onda poderiam ser atendidos alguns milhões de terminais [6]. Isto poderia permitir a realização de uma alternativa de rede "sem comutação" de nível único ao atual paradigma de redes de transporte de múltiplos níveis baseada em um número relativamente grande de nós de alta capacidade de processamento. A rede proposta poderia eliminar a necessidade de cross-connects ATM, roteadores IP ou SDH e de cross-connects ópticos dentro da rede de transporte. Só haveria necessidade de um único nó roteador de comprimentos de onda [6], [7]. Por outro lado, a rede proposta depende do desenvolvimento de terminais sintonizáveis de alta velocidade de comutação em comprimentos de onda e que estejam aptos a receber ou transmitir todos os comprimentos de onda em uso. Quanto maior for a rede, mais 
comprimentos de onda utilizará, e maior será a complexidade dos terminais. Isto obviamente implicará num aumento de custo, que limitará o crescimento da rede.

$\mathrm{Na}$ Seção 2.2 será descrita a estrutura da rede, bem como o seu funcionamento. Na Seção 2.3 será detalhada a seqüência de conversores de comprimentos de onda, que é uma parte essencial da rede. Nas Seções 2.4 a 2.9 serão descritos os principais componentes de uma rede óptica sem comutação.

\subsection{Estrutura da rede sem comutação}

A estrutura de uma rede óptica sem comutação é mostrada na Fig. 2.1 [7]. Existe um conjunto de $N_{p}$ PONs interconectadas por um nó roteador de comprimentos de onda passivo (PWRN) [5]-[7]. As PONs são redes ópticas passivas que se espalham pela área geográfica a ser atendida, subdividindo-se para atender terminais de sintonia rápida. O PWRN é a figura central de toda a estrutura da rede.

O PWRN é essencialmente um roteador de redes de guias de onda (WGR) [8]-[10]. O acesso ao meio constituído pelas PONs é disciplinado utilizando-se um esquema WDMA / TDMA administrado por um controlador de rede centralizado. Os comprimentos de onda nas fibras ópticas de acesso, conectando cada PON com sua correspondente porta de entrada no PWRN, são arranjados de tal forma que cada comprimento de onda se direciona a uma diferente porta de saída do PWRN e, por conseguinte, a uma diferente PON a ser conectada. Dessa forma, existe uma conexão direta entre quaisquer pares de PONs, por intermédio de um comprimento de onda dedicado. A Fig. 2.2 mostra um exemplo de alocação de comprimentos de onda em um PWRN.

Em cada comprimento de onda o tempo é dividido em uma seqüência de slots. Cada slot de tempo pertinente a um determinado comprimento de onda pode ser usado por apenas um dos terminais conectados à mesma porta do roteador. Por exemplo: um cliente $X$ da PON $N$ pode se comunicar com o cliente $Y$ da PON $M$, por meio de um slot de tempo no comprimento de onda que conecta diretamente a PON $N$ com a PON $M$ através do PWRN. 


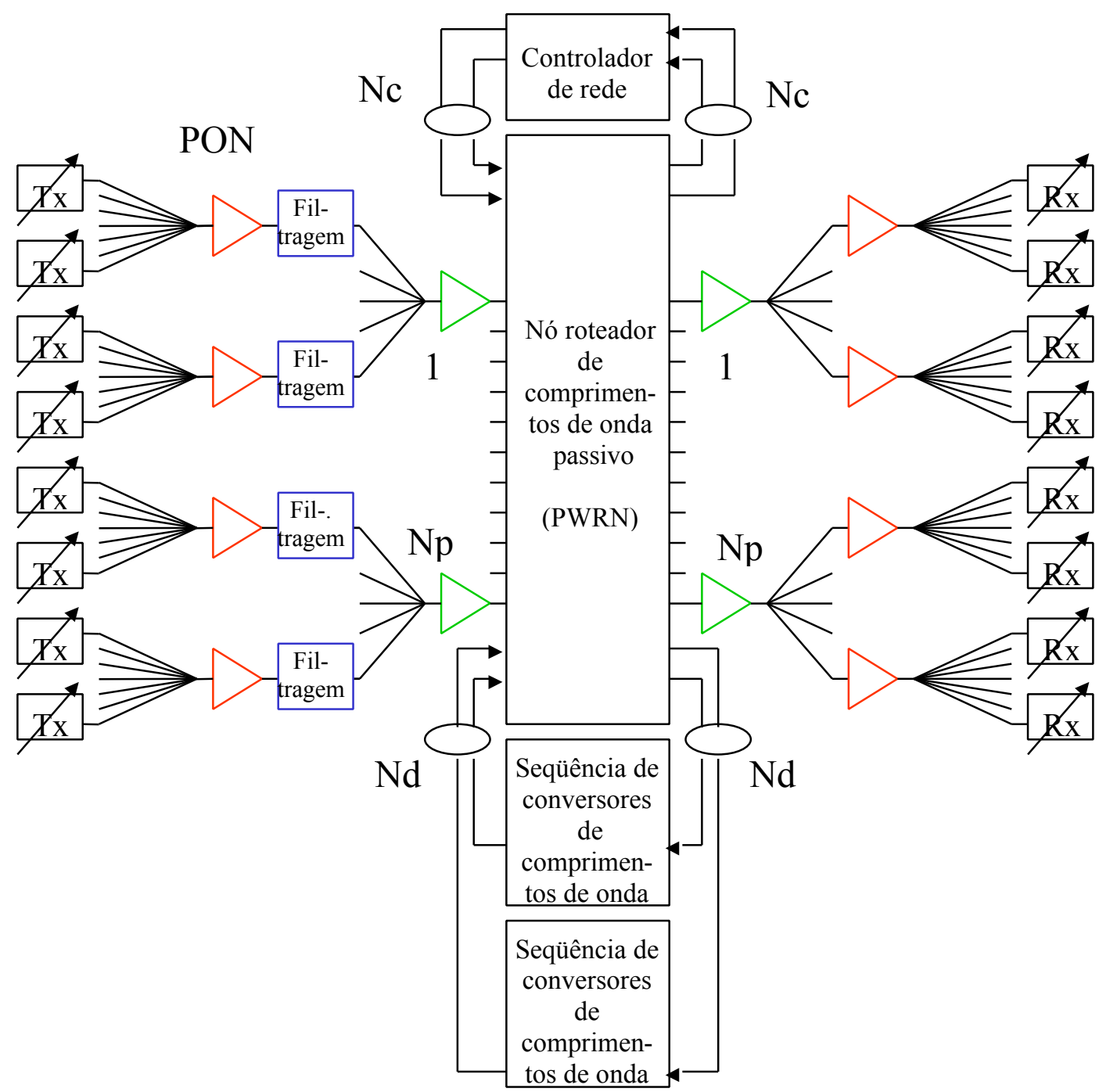

Figura 2.1. Estrutura de uma rede óptica sem comutação [7]

Um controlador de rede centralizado tem a função de designar os slots de tempo para os clientes. Um protocolo de sinalização é utilizado pelo controlador de rede para se comunicar com todos os clientes, através de canais dedicados. $\mathrm{Ou}$ seja, um comprimento de onda é destacado para as comunicações entre o controlador e todos os clientes pertencentes a uma PON. Uma quantidade, $N_{c}$, de portas do PWRN é dedicada à interconexão entre os terminais de rede e o controlador de rede. Para a comunicação entre um par qualquer de terminais, o transmissor e receptor correspondentes devem ser sintonizados no comprimento de onda que conecta, através do PWRN, as PONs às quais pertencem esses terminais, e no slot de tempo designado. 
Se houver a necessidade do uso de amplificadores em cascata, então será preciso filtrar o ruído introduzido pelos mesmos antes do último combinador anterior ao PWRN.

Com o intuito de obter um elevado grau de flexibilidade na utilização da capacidade da rede, são introduzidas as seqüências de conversores de comprimentos de onda (CCO), que são controladas pelo controlador de rede. Essas seqüências são conectadas a um certo número, $N_{d}$, de portas auxiliares do PWRN, denominadas "portas reservas". Dessa maneira, em função das necessidades de tráfego, um número variável de comprimentos de onda pode ser designado dinamicamente entre pares de grupos de terminais. Essa capacidade adicional é usada para suportar o fluxo de tráfego que extravasa (excedente) dos comprimentos de onda que conectam diretamente as PONs. Caso a capacidade do comprimento de onda que suporta diretamente as comunicações entre um par de PONs seja ultrapassada, conexões adicionais podem ser supridas pelos slots de tempo pertinentes aos comprimentos de onda que conectam as PONs com as portas reservas. Nesse caso, uma chamada é roteada da PON fonte em direção a PON de destino, via conversão de comprimentos de onda, por meio da utilização de um slot de tempo vago dentro do comprimento de onda que conecta a PON fonte com uma porta reserva. Em seguida é utilizado o correspondente slot de tempo no comprimento de onda que conecta essa porta reserva com a PON de destino.

Em resumo, cada fibra de entrada conectada no PWRN conduz $N$ comprimentos de onda, cada um deles dedicado à transmissão entre a porta de entrada pertinente e uma porta de saída específica. Reciprocamente, cada fibra conectada às portas de saída conduz $N$ comprimentos de onda que vêm de diferentes portas de entrada. Em cada comprimento de onda o tempo é dividido em $T$ slots.

É mostrada na Fig. 2.2 a alocação sem conflito de oito comprimentos de onda em uma PWRN caracterizada por $N_{p}=6$ e $N_{d}=2\left(N_{c}=0\right)$. A entrada $(i$, j) da matriz indica o comprimento de onda que conecta a i-ésima porta de entrada com a j-ésima porta de saída. Por exemplo, a conexão entre a porta de entrada 3 e a porta de saída 4 pode ser feita através de três caminhos: a) via comprimento de 
onda direto $\lambda_{2}$; b) via seqüência formada pelos comprimentos de onda $\lambda_{5}$ (que conecta a porta de entrada com a porta reserva 7) e $\lambda_{6}$ após a conexão; c) via seqüência formada pelos comprimentos de onda $\lambda_{6}$ (que conecta a porta de entrada com a porta reserva 8) e $\lambda_{5}$, após a conversão.

\begin{tabular}{|c|c|c|c|c|c|c|c|c|c|c|}
\hline & \multicolumn{8}{|c|}{ Portas de saída } \\
\hline & & & \multicolumn{6}{|c|}{$\mathrm{Np}$} & \multicolumn{2}{|c|}{$\mathrm{Nd}$} \\
\hline & & & 1 & 2 & 3 & 4 & 5 & 6 & 7 & 8 \\
\hline \multirow{5}{*}{$\begin{array}{l}\text { Por- } \\
\text { tas }\end{array}$} & \multirow{6}{*}{$\mathrm{Np}$} & 1 & $\lambda_{1}$ & $\lambda_{2}$ & $\lambda_{3}$ & $\lambda_{4}$ & $\lambda_{5}$ & $\lambda_{6}$ & $\lambda_{7}$ & $\lambda_{8}$ \\
\hline & & 2 & $\lambda_{8}$ & $\lambda_{1}$ & $\lambda_{2}$ & $\lambda_{3}$ & $\lambda_{4}$ & $\lambda_{5}$ & $\lambda_{6}$ & $\lambda_{7}$ \\
\hline & & 3 & $\lambda_{7}$ & $\lambda_{8}$ & $\lambda_{1}$ & $\lambda_{2}$ & $\lambda_{3}$ & $\lambda_{4}$ & $\lambda_{5}$ & $\lambda_{6}$ \\
\hline & & 4 & $\lambda_{6}$ & $\lambda_{7}$ & $\lambda_{8}$ & $\lambda_{1}$ & $\lambda_{2}$ & $\lambda_{3}$ & $\lambda_{4}$ & $\lambda_{5}$ \\
\hline & & 5 & $\lambda_{5}$ & $\lambda_{6}$ & $\lambda_{7}$ & $\lambda_{8}$ & $\lambda_{1}$ & $\lambda_{2}$ & $\lambda_{3}$ & $\lambda_{4}$ \\
\hline \multirow{3}{*}{$\begin{array}{l}\text { en- } \\
\text { trada }\end{array}$} & & 6 & $\lambda_{4}$ & $\lambda_{5}$ & $\lambda_{6}$ & $\lambda_{7}$ & $\lambda_{8}$ & $\lambda_{1}$ & $\lambda_{2}$ & $\lambda_{3}$ \\
\hline & \multirow{2}{*}{$\mathrm{Nd}$} & 7 & $\lambda_{3}$ & $\lambda_{4}$ & $\lambda_{5}$ & $\lambda_{6}$ & $\lambda_{7}$ & $\lambda_{8}$ & $\lambda_{1}$ & $\lambda_{2}$ \\
\hline & & 8 & $\lambda_{2}$ & $\lambda_{3}$ & $\lambda_{4}$ & $\lambda_{5}$ & $\lambda_{6}$ & $\lambda_{7}$ & $\lambda_{8}$ & $\lambda_{1}$ \\
\hline
\end{tabular}

Figura 2.2. Exemplo de alocação sem conflito de comprimentos de onda, para uma PWRN 8x8 com $N_{p}=6$ e $N_{d}=2$.

Em estudos baseados em dimensionamentos aproximados preliminares considerando redes com centenas de milhares de terminais estima-se que redes desse tipo poderiam prover uma taxa média de $5 \mathrm{Mb} / \mathrm{s}$ para o cliente (sem se importar com a destinação do tráfego) [7].

\subsection{Estrutura da seqüência de conversores de comprimentos de onda}

Uma seqüência de conversores de comprimentos de onda (Fig. 2.3) é composta por um demultiplexador WDM e um certo número de conversores de comprimento de onda. Esse número de conversores é igual ao número de PONs, $N_{p}$. A saída de cada conversor é controlada por um laser de bombeio sintonizável. O controlador de rede determina o comprimento de onda dos lasers sintonizáveis. Os sinais de saída são combinados num combinador óptico passivo e, em seguida, amplificados por um SOA ou outro dispositivo de amplificação. 
Desse ponto em diante os sinais são conduzidos por uma fibra até uma das portas de entrada. A Fig. 2.3 mostra a estrutura de uma seqüência de conversores de comprimento de onda.

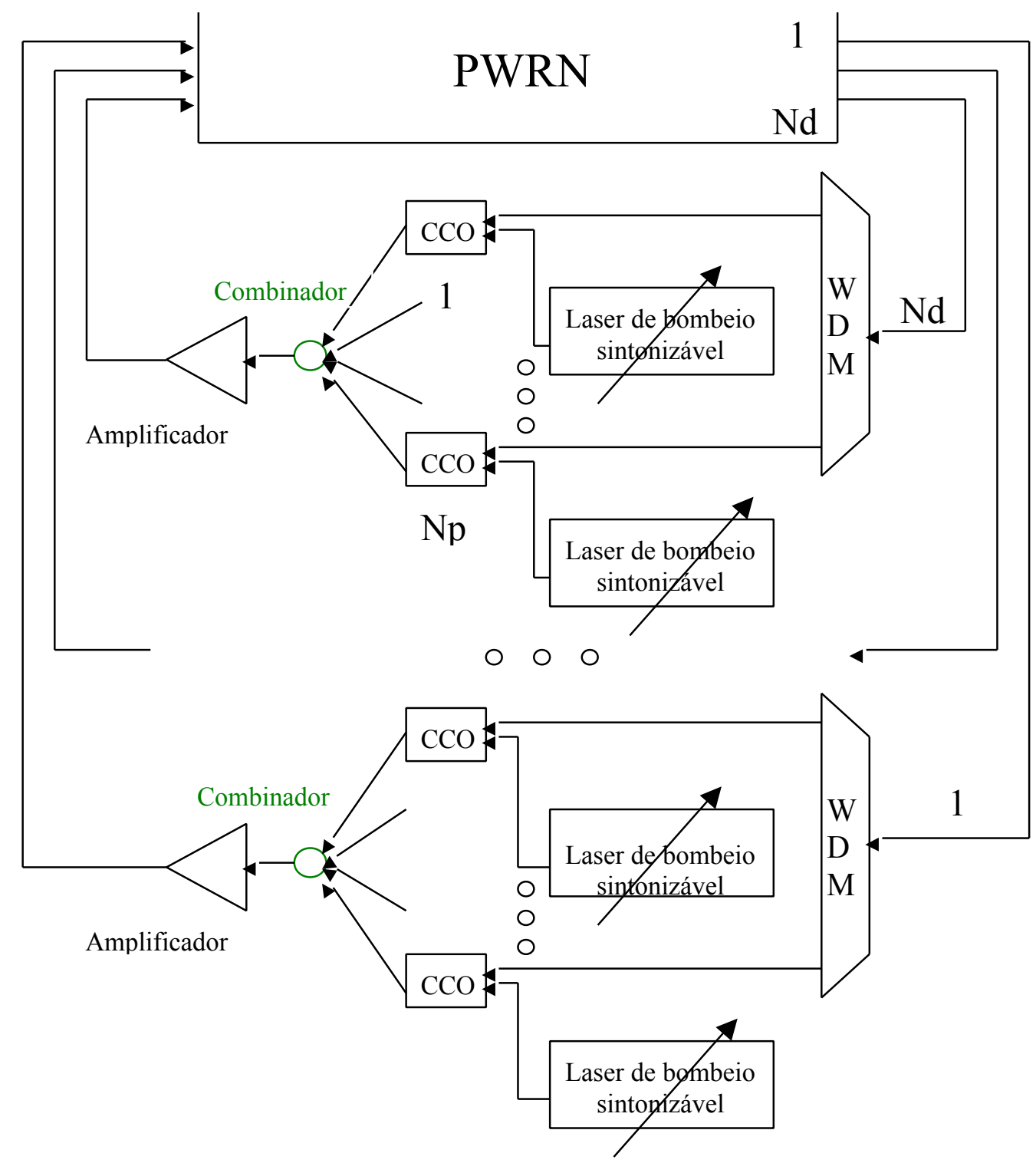

Figura 2.3. Estrutura de uma seqüência de conversores de comprimentos de onda (CCO) [7]

\subsection{Roteador de rede com guias de onda (WGR - waveguide grating router)}

Um WGR é um roteador de comprimentos de onda que utiliza duas estrelas passivas [8]-[10]. O WGR não contém partes móveis, sendo, portanto, estático. É considerado passivo porque a trajetória a ser seguida por um sinal só depende de 
seu comprimento de onda e da porta por onde entra. O WGR não altera as trajetórias entre portas definidas desde a sua fabricação. As estrelas passivas são acopladores ópticos que conectam um conjunto de fibras de entrada a outro conjunto de fibras de saída.

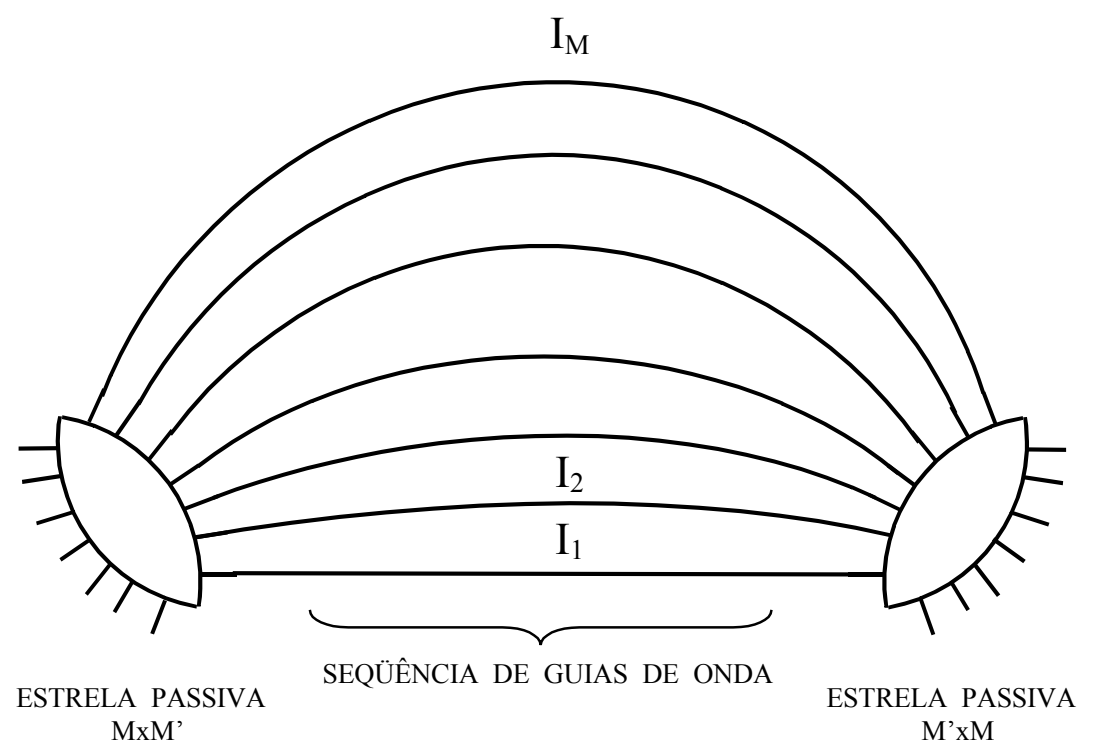

Figura 2.4. Roteador de rede com guias de onda (WGR).

O WGR consiste de duas estrelas passivas conectadas por fibras ópticas de comprimento apropriado, conforme esquema mostrado na Fig. 2.4. A estrela passiva de entrada possui $M$ entradas e $M^{\prime}$ saídas, sendo que $M \leq M^{\prime}$. A estrela passiva de saída é um dispositivo recíproco, ou seja, possui $M^{\prime}$ entradas e M saídas. Na primeira estrela passiva, um sinal em um determinado comprimento de onda entrando por qualquer das portas de entrada é dividido e transmitido para as $M^{\prime}$ fibras ópticas. O sinal trafega através dos guias de onda experimentando uma mudança de fase diferente em cada fibra, que depende do comprimento do guia de onda e do comprimento de onda do sinal. Na entrada da segunda estrela passiva, a diferença de fase no sinal será tal que o mesmo só será recombinado construtivamente em uma única porta de saída. Dois sinais do mesmo comprimento de onda chegando de duas portas de entrada diferentes não vão 
interferir mutuamente nos guias de onda da conexão porque há uma diferença de fase adicional criada pela distância entre as duas portas de entrada [10]. Os sinais serão combinados nos guias de onda, mas serão separados novamente na segunda estrela passiva e direcionados para portas de saída diferentes.

\subsection{Redes ópticas passivas (PONs)}

São sistemas ópticos de distribuição sem componentes ativos localizados entre o WGR e os terminais de rede, ou, quando houver, unidades de rede ópticas (ONUs) [17]. O princípio básico de uma PON é repartir o acesso a uma porta do WGR entre muitos terminais de rede. Essa divisão diminui a quantia de gasto de capital em rede que será suportada por cada cliente [18].

\subsection{Conversão de comprimentos de onda}

A capacidade de converter dados de um comprimento de onda para outro torna reconfiguráveis os sistemas que utilizam conversão de comprimentos de onda. Isso reduz a probabilidade de bloqueio em tais redes. Conversão de comprimento de onda pode ser obtida por meio de detecção de um sinal óptico e pela subseqüente modulação de um laser para um outro comprimento de onda. Para evitar essa conversão optoeletrônica adicional e vice-versa, a conversão de comprimentos de onda por meios totalmente ópticos é preferível.

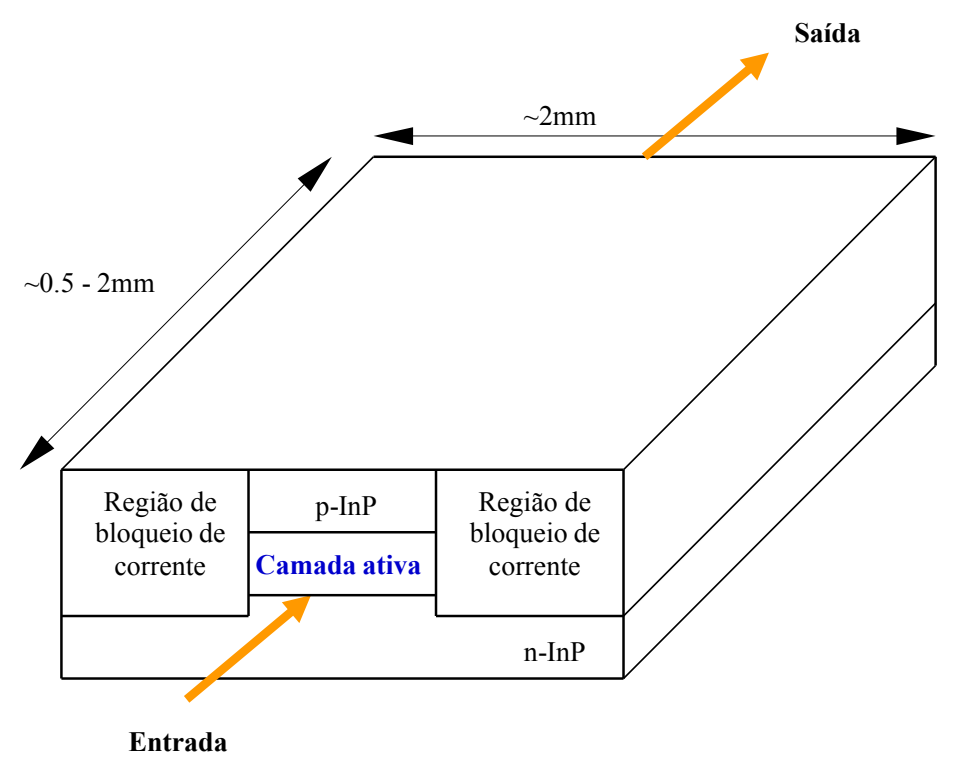

Figura 2.5. Uma típica estrutura de dispositivo amplificador óptico em semicondutor [12] 
Muitas técnicas têm sido exploradas para se obter conversão de comprimentos de onda totalmente óptica. Como exemplo, conversores utilizando as fracas não-linearidades ópticas da sílica tem sido pesquisados em fibras monomodo [12]. Embora as não-linearidades permitam atuação rápida e os dispositivos tenham demonstrado um bom desempenho, os componentes baseados em fibra são problemáticos devido à necessidade de comprimentos variando entre 1 e $10 \mathrm{~km}$ [12]. Existe também a dificuldade na integração do dispositivo em fibra com os componentes semicondutores optoeletrônicos.

Por outro lado, os amplificadores ópticos em semicondutores são dispositivos de conversão de comprimentos de onda totalmente ópticos baseados em semicondutor [12]. São compactos e se prestam prontamente à integração e produção em massa usando técnicas de fabricação similares às usadas para circuitos integrados em semicondutor. $\mathrm{O}$ dispositivo baseado em semicondutor usa as não-linearidades em um amplificador óptico semicondutor (SOA) para fazer a conversão de comprimentos de onda [12], [13]. Esses dispositivos foram desenvolvidos originalmente para amplificação linear para estender o alcance dos sistemas de transmissão por fibra. Sistemas de comunicação ópticas de alta capacidade empregando WDM para utilizar plenamente a largura de banda disponível podem usar um SOA para compensar as perdas de transmissão e divisão [14]. Entretanto, as não-linearidades são agora exploradas para conversão de comprimentos de onda.

Um diagrama esquemático do SOA é mostrado na Fig. 2.5. O SOA consiste de uma heterojunção p-n diretamente polarizada, através da qual a corrente flui, e um guia de ondas óptico para confinar a luz entrante na região ativa que faz a amplificação. Camadas anti-reflexivas são aplicadas nas faces de entrada e saída do dispositivo para prevenir realimentação óptica, o que faria o SOA atuar como um laser.

O ganho de um SOA varia em função da potência do sinal óptico que penetra na região ativa, conforme pode ser observado na Fig. 2.6.b. Para potências de entrada maiores, o ganho do SOA é reduzido e esse efeito é conhecido como saturação de ganho [15], ocorrendo tipicamente para potências de entrada da ordem de $100 \mu \mathrm{W}$ ou mais [12]. 
Comprimento de onda alvo

(a)

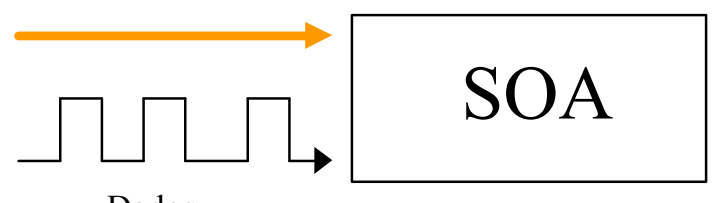

Dados
Comprimento de onda convertido

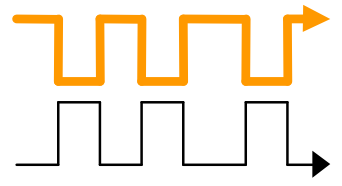

(b)

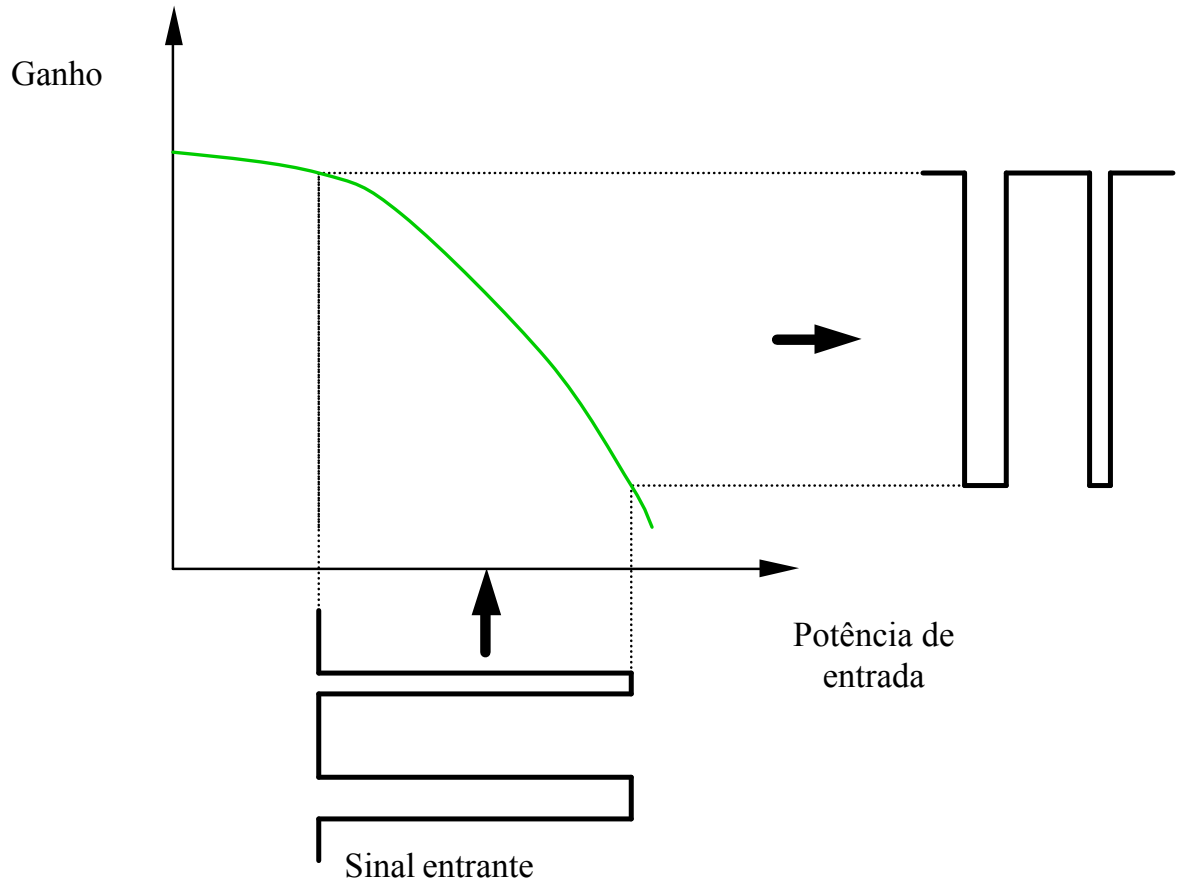

Figura 2.6. Conversor de comprimentos de onda SOA por modulação de ganho cruzado: (a) Princípio de operação [12]; (b) Característica da saturação de ganho [15].

A saturação de ganho pode ser usada para converter dados de um comprimento de onda para outro [12]-[13] conforme mostrado na Fig. 2.6.a. Dois sinais ópticos entram num único SOA, com um deles levando dados modulados em amplitude e o outro sendo de potência constante $(\mathrm{CW})$. Se a potência óptica de pico no sinal modulado é próxima da potência de saturação do SOA, o ganho será modulado em sincronismo com as variações de potência. Quando o sinal de dados está em um nível alto (1 binário), o ganho é pequeno, e vice-versa. A modulação 
em ganho é imposta ao feixe luminoso de entrada não-modulado. Assim, uma réplica invertida dos dados de entrada é criada no comprimento de onda alvo [12][13].

Os SOAs são dispositivos versáteis que podem ser usados tanto para amplificação como para conversão de comprimentos de onda.

\subsection{Transmissores sintonizáveis}

Transmissor óptico sintonizável é um dispositivo que emite o sinal óptico com as informações a serem transmitidas ao receptor de destino, podendo ter o comprimento de onda da transmissão alterado por um controlador externo. A sintonização do comprimento de onda da emissão visa permitir o roteamento correto do sinal até o destino.

Os transmissores ópticos sintonizáveis são baseados em laser semicondutor sintonizável. Existem modelos cuja faixa de sintonia resulta da variação do índice de refração em função da temperatura [19]. Um transmissor de sintonia rápida em comprimentos de onda proposto em [20] é baseado em um laser com uma seção de ganho e três seções de corrente para sintonia. Uma corrente constante é injetada através da seção de ganho para o bombeio da região ativa. A sintonia em comprimento de onda é obtida pela injeção de correntes em cada seção de sintonia para variar o índice de refração da cavidade do laser. Baseado nesse laser foi construído um transmissor de sintonia rápida que pode ser sintonizado em 100 canais de comprimento de onda. Esse laser tem uma faixa de sintonia de $44 \mathrm{~nm}$ $(1523,77-1567,77$ nm). O tempo de comutação de canais é menor que 100 ns.

\subsection{Receptores sintonizáveis}

Receptor óptico sintonizável é um dispositivo que pode ser sintonizado pelo controlador de rede no comprimento de onda em que estão as informações a ele destinadas por um transmissor óptico sintonizável. A sintonia do comprimento de onda de recepção, designado pelo controlador de rede, visa permitir que o sinal emitido pelo transmissor correspondente seja recebido, convertido em sinal elétrico, e disponibilizado para o meio metálico de destino. 
Uma abordagem de receptor óptico de sintonia é a combinação de um demultiplexador óptico com um arranjo de fotodetectores. O demultiplexador óptico separa todos os canais de comprimento de onda para os fotodetectores. Seleciona-se o canal por meio da ativação do fotodetector correspondente [21].

\subsection{Unidades de rede ópticas (ONU)}

São unidades em que o uso dos terminais de rede nelas contidos é compartilhado por vários clientes. Na ONUs é feita a conversão eletro-óptica dos sinais. A rede entre uma ONU e os aparelhos dos clientes pode ser metálica [22], [23].

\subsection{Conclusões}

A estrutura descrita neste capítulo pode ser utilizada para várias escalas de rede e várias dimensões de áreas geográficas, numa concepção relativamente simples, pois se utiliza apenas um nó roteador. As relações entre o número de clientes, o correspondente tráfego, e os diversos parâmetros da rede serão modeladas no Capítulo 4, utilizando-se o estudo do tráfego em sistemas de telecomunicações, exposto no Capítulo 3.

$\mathrm{Na}$ estrutura estudada, foi considerado que um terminal óptico com transmissor e receptor sintonizáveis estivesse disponível para cada cliente. Esse sistema, conhecido por "fiber to the home" (FTTH), teria, porém, um alto custo. Com a finalidade de reduzir os custos, pode-se instalar unidades de rede óptica $(\mathrm{ONU})$ em nós remotos, que poderiam ficar em lugares protegidos da rede externa nas vias públicas, atendendo a um certo número de clientes. Assim, os custos diminuiriam. A probabilidade do bloqueio da ONU causado quando dois ou mais clientes tentarem se comunicar utilizando o mesmo slot de tempo é muito menor que a probabilidade de bloqueio da rede óptica sem comutação como um todo [7].

Após a ONU podem ser consideradas várias arquiteturas de acesso, que consistem em soluções denominadas FTTC (fibra para a vizinhança) [23]. 


\section{CAPÍTULO 3}

TRÁFEGO

\section{TELECOMUNICAÇÕES}

EM

SISTEMAS

DE

\subsection{Introdução}

É de extrema importância dimensionar as redes de telecomunicações de forma que consigam escoar satisfatoriamente o tráfego que devem suportar, usando a menor quantidade possível de equipamentos, com o objetivo de minimizar os custos. Para isso, é necessário calcular corretamente o tráfego a ser suportado.

Neste capítulo se fará uma abordagem da teoria de tráfego com este objetivo.

\subsection{Compartilhamento de recursos}

Para tornar economicamente viável um sistema de telecomunicações, percebeu-se bem cedo que era necessário compartilhar muitos de seus recursos. Esse compartilhamento introduziu a possibilidade de não se poder atender todas as solicitações de serviço. Surgiu então a questão: qual seria a quantidade de recursos necessária para que a quantidade de serviço solicitada e negada (ou retardada) ficasse abaixo de um nível pré-especificado aceitável?

No Brasil, até meados dos anos 70, o tráfego interurbano intra-estadual de telecomunicações era em grande parte suportado por troncos constituídos de fios metálicos nus suportados por postes. No interior do Estado de São Paulo, a Companhia Telefônica Brasileira, e sua sucessora, a TELESP, operaram os então denominados troncos Sorocaba-Glicério, Bauru-Tupã, Botucatu-Ourinhos, entre outros. Esses troncos e suas derivações geralmente terminavam em mesas operadas manualmente por telefonistas. Era preciso na época estipular a quantidade de telefonistas (recursos humanos) necessária para a operação do sistema. Não era incomum na ocasião a demora de várias horas para se conseguir 
completar uma chamada interurbana. Evidentemente esse sistema não estava bem dimensionado. O número de troncos era insuficiente para que a quantidade de serviço solicitada e negada (ou retardada) ficasse abaixo de um nível aceitável.

A característica comum de situações de compartilhamento de recursos é que, tanto os instantes em que são feitas solicitações de serviços por clientes, como as durações dos intervalos de tempo de ocupação dos recursos, só podem ser previstos em um sentido estatístico.

Os modelos de compartilhamento de recursos geralmente podem ser definidos em termos de três características: processo de entrada, mecanismo de serviço e disciplina de fila.

O processo de entrada descreve a seqüência de solicitações de serviço. $O$ mecanismo de serviço trata de peculiaridades como o número de recursos e os intervalos de tempo em que os clientes ocupam os recursos. A disciplina de fila especifica a decisão a ser tomada em relação aos clientes que encontram todos os recursos ocupados. Eles poderão ter que deixar o sistema imediatamente ou poderão esperar pelo serviço em uma fila.

\subsection{Congestionamento}

Quando se compartilham recursos é importante medir o congestionamento, situação em que recursos são solicitados e negados ou há um retardo em seu atendimento. Existem dois métodos de medição de congestionamento [24].

Um dos métodos consiste na obtenção da medida conhecida como congestionamento temporal ou probabilidade de bloqueio do sistema. Por este método se mede a situação da utilização plena dos recursos, obtida pela proporção de tempo em que todos eles estão utilizados. Para se obter experimentalmente a medida de um congestionamento temporal em um grupo de recursos compartilhados, efetua-se amostragens no grupo em instantes escolhidos aleatoriamente para se verificar se todos os recursos estão ocupados ou não. A partir daí determina-se a proporção de amostras em que o grupo de recursos está totalmente utilizado. Este método pode ser utilizado para obtenção do congestionamento temporal em um grupo de troncos telefônicos.

O segundo método consiste na obtenção da medida denominada congestionamento de chamadas. Este método consiste em se medir a freqüência 
que um recurso solicitado é negado. Esta medida é dada pela fração de solicitações de recursos negadas dentre o total de solicitações feitas. A obtenção experimental dessa medida em telefonia é feita efetuando-se chamadas por meio de um telefone e obtendo-se a proporção das que não foram completadas entre o total de chamadas feitas. Este tipo de medição pode ser utilizado na obtenção de indicadores das metas de qualidade de serviço da ANATEL.

O congestionamento temporal e o congestionamento de chamadas exibem valores muito próximos, principalmente quando há um número elevado de recursos compartilhados disponíveis [24].

\subsection{Fórmula Erlang B}

Consideremos a situação em que clientes de uma central telefônica compartilhem um conjunto de $s$ troncos telefônicos quando precisarem efetuar uma chamada. Suponhamos que a disciplina de fila seja tal que as chamadas que encontrem todos os troncos ocupados sejam imediatamente eliminadas do sistema. Deseja-se determinar qual é a proporção de chamadas perdidas [25].

É importante obter uma expressão que permita calcular qual é a proporção de chamadas perdidas em função da demanda. Essa fórmula deve permitir a estimativa do número de troncos necessários para atingir um critério de serviço pré-estabelecido, levando-se em consideração a carga de tráfego telefônico prevista.

Denotemos por $N$ o conjunto dos números naturais. $\mathrm{O}$ sistema em estudo é considerado em estado $E_{j}(0 \leq j \leq s, j \in N)$ quando o número de clientes que o utilizam é $j$. Seja $P_{j}$ a proporção de tempo em que o sistema permanece no estado $E_{j}$. Essa proporção de tempo é relativa à razão entre o tempo de permanência no estado $E_{j}$ e a somatória dos tempos em que o sistema permanece em qualquer dos $s$ estados possíveis. Segue-se que $P_{j}$ será também a proporção de tempo que $j$ troncos estão ocupados. Seja $\lambda$ a taxa de chegada de chamadas. Isto significa que $\lambda$ é o número médio de solicitações de serviço por unidade de tempo. 
Consideremos primeiramente o caso em que $j<s$. As chamadas chegam com taxa $\lambda$ e a proporção de tempo que o sistema permanece no estado $E_{j}$ é $P_{j}$. Isso implica em que a taxa que a transição $E_{j} \rightarrow E_{j+1}$ acontece, ou seja, a média de ocorrências dessa transição por unidade de tempo, é $\lambda P_{j}$. Consideremos em seguida a situação em que $j=s$. Como o estado $E_{s+1}$ representa um estado fisicamente impossível, porque existem apenas $s$ troncos, a taxa que a transição $E_{s} \rightarrow E_{s+1}$ ocorre é zero. Conclui-se que a taxa que a transição ascendente $E_{j} \rightarrow E_{j+1}$ acontece é $\lambda P_{j}$ para $0 \leq j<s, j \in N$ e 0 para $j=s$.

Analisemos agora a transição descendente $E_{j+1} \rightarrow E_{j}(0 \leq j<s, j \in N)$. Denominemos $\tau$ o tempo médio em que uma chamada ocupa um tronco. Isso implica em que, se um único tronco está ocupado, a média de chamadas terminando durante um intervalo de tempo $\tau$ é 1 , o que significa que a taxa de terminação para uma única chamada é $1 / \tau$. Da mesma forma, se duas chamadas estão acontecendo simultaneamente, a média de chamadas terminando durante um intervalo de tempo $\tau$ é 2, o que significa que a taxa de terminação para duas chamadas simultâneas é $2 / \tau$. Utilizando-se o mesmo raciocínio, conclui-se que é $\frac{j+1}{\tau}$ a taxa de terminação para $j+1$ chamadas simultâneas. Como a proporção de tempo que o sistema permanece no estado $E_{j+1}$ é $P_{j+1}$, decorre que a transição descendente $E_{j+1} \rightarrow E_{j}$ ocorre à taxa de $(j+1) \tau^{-1} P_{j+1}$ transições por unidade de tempo $(0 \leq j<s, j \in N)$.

Aplica-se a seguir o princípio de conservação do fluxo. Para $\forall j, 0 \leq j<s$, $j \in N$, iguala-se a taxa de ocorrência da transição ascendente $E_{j} \rightarrow E_{j+1}$ à taxa de ocorrência da transição descendente $E_{j+1} \rightarrow E_{j}$. Tem-se então a equação de equilíbrio estatístico ou da conservação do fluxo [25]:

$$
\lambda P_{j}=(j+1) \tau^{-1} P_{j+1} \quad(0 \leq j<s, j \in N)
$$


Resolvendo-se essas equações por recorrência, o resultado obtido [25] que expressa $P_{j}$ em função de $P_{0}$ é:

$$
P_{j}=\frac{(\lambda \tau)^{j}}{j !} P_{0} \quad(0<j \leq s, j \in N)
$$

Como os números $\left\{P_{j}\right\}$ são proporções relativas à razão entre o tempo de permanência no estado $E_{j}$ e a somatória dos tempos em que o sistema permanece em qualquer dos $s$ estados possíveis, devemos ter :

$$
P_{0}+P_{1}+\ldots+P_{s}=1
$$

De (3.2) e (3.3) decorre que:

$$
P_{0}+P_{1}+\ldots+P_{s}=1=P_{0} \sum_{k=0}^{s} \frac{(\lambda \tau)^{k}}{k !}
$$

Resolvendo-se (3.4) para $P_{0}$, obtém-se:

$$
P_{0}=\left[\sum_{k=0}^{s} \frac{(\lambda \tau)^{k}}{k !}\right]^{-1}
$$

De (3.2) e (3.5) obtém-se:

$$
P_{j}=\frac{\frac{(\lambda \tau)^{j}}{j !}}{\sum_{k=0}^{s} \frac{(\lambda \tau)^{k}}{k !}} \quad(0 \leq j \leq s, j \in N)
$$

A equação (3.6) fornece a proporção de tempo $P_{j}$ em que $j$ troncos estão ocupados. 
Pode-se observar em (3.6) que $P_{j}$ depende de $\lambda$ (taxa de chegada de chamadas) e de $\tau$ (tempo médio em que uma chamada ocupa um tronco) apenas por meio do produto $\lambda \tau$ [25]. Tal produto é uma medida da demanda do sistema denominada carga oferecida, e é denotada por $a$. Os valores numéricos de $a$ são expressos em unidades denominadas erlang (erl).

Quando $j=s$, (3.6) pode ser reescrita na forma

$$
P_{s}=\frac{\frac{a^{s}}{s !}}{\sum_{k=0}^{s} \frac{a^{k}}{k !}}
$$

O lado direito de (3.7) é denotado por $B(s, a)$. A expressão (3.7) é conhecida como fórmula Erlang B [7], fórmula de bloqueio de Erlang [24], ou fórmula de perda de Erlang [25]. Conhecendo-se os valores de $a$, que é a carga oferecida, e $s$, que é o número de troncos (recursos) compartilhados, pode-se obter por meio de (3.7) a proporção de tempo $P_{s}$ em que todos os $s$ troncos estão ocupados.

Para a dedução de (3.7) estabeleceu-se para o processo de entrada apenas a taxa de chegada de chamadas. Assim sendo, a conclusão vale inclusive para um processo de entrada especial denominado processo de Poisson. Para o mecanismo de serviço, só foi especificado o tempo em que uma chamada ocupa um tronco (tempo de serviço) por meio da sua média. Em. conseqüência, a fórmula Erlang B é válida para qualquer distribuição de tempos de serviço. Portanto, vale também para uma distribuição exponencial de tempos de serviço.

Pode-se mostrar [25] que a fórmula Erlang B fornece também a proporção de solicitações de serviço (chamadas) que encontram todos os troncos ocupados, sendo portanto eliminadas do sistema, quando o processo de entrada ocorre de acordo com um processo de Poisson. 


\subsection{Processo de Poisson}

Consideremos os instantes em que chegam solicitações de serviço por clientes. Denotemos esses instantes por $T_{1}, T_{2}, T_{3}, \ldots, T_{j}, \ldots$ Consideremos $T_{0}=0$. Levemos em consideração a variável aleatória $X_{j}=T_{j}-T_{j-1} \quad(\mathrm{j}=1,2,3, \ldots)$

Tem-se um processo de Poisson quando os instantes de chegada obedecerem as seguintes condições [24], [25]:

1. As durações dos intervalos de tempo entre instantes sucessivos são independentes;

2. Essas durações dos intervalos têm a seguinte distribuição exponencial:

$$
P\left\{X_{j}>t\right\}=e^{-\Lambda t} \quad(j=1,2,3, \ldots)
$$

onde $\Lambda$ é uma constante considerada como taxa do processo de Poisson

\subsection{Extravasamento de tráfego de um grupo primário de recursos}

Consideremos um sistema composto pela seqüência de um grupo primário de $s$ recursos e um grupo secundário de extravasamento com infinitos recursos, conforme mostrado na Figura 3.1. Nesse sistema, denominado modelo de extravasamento simples, considera-se que os clientes solicitem serviços inicialmente ao grupo primário e, caso encontrem todos os $s$ recursos ocupados, as solicitações são direcionados para o grupo secundário de extravasamento com infinitos recursos.

Consideremos que seja $a$ a carga oferecida ao grupo primário. Seja $P(j, k)$ a probabilidade do equilíbrio estatístico em que $j$ clientes estão ocupando recursos no grupo primário, ao mesmo tempo em que $k$ clientes estão ocupando recursos no grupo secundário. Considera-se que o processo de entrada seja de Poisson. Admite-se para o mecanismo de serviço, que a distribuição dos tempos de serviço seja exponencial. 


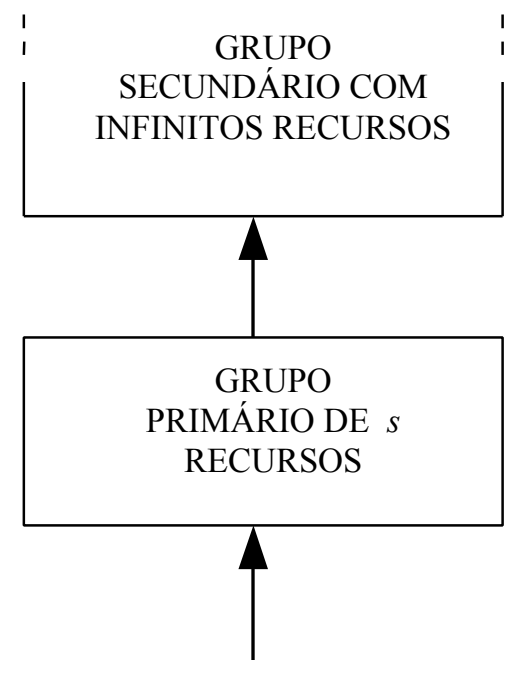

CARGA OFERECIDA $=a$ erl

Figura 3.1. Modelo de extravasamento simples.

Pode-se provar que a média $\alpha$ e a variância $v$ relativas à carga que é rejeitada pelo grupo primário de recursos (fluxo de extravasamento) são dadas respectivamente por [25]:

$$
\alpha=a B(s, a)
$$

$\mathrm{e}$

$$
v=\alpha\left(1-\alpha+\frac{a}{s+1+\alpha-a}\right)
$$

onde $B(s, a)$ é a fórmula Erlang $\mathrm{B}, a$ é a carga oferecida ao grupo primário de recursos (erl) e $s$ é o número de recursos do grupo primário. 


\subsection{Extravasamento de tráfego de um conjunto de vários grupos primários de recursos}

Consideremos um sistema em que existem $n$ grupos primários de recursos, nos quais os processos de entrada são de Poisson. Todas as solicitações de serviços de clientes que encontrem todos os recursos de seu grupo ocupados são direcionadas para um único grupo secundário de extravasamento. Os mecanismos de serviço de todos os grupos são idênticos ao descrito na seção anterior. Acrescentamos apenas que os tempos de serviço dos grupos são independentes entre si. A disciplina de fila especificada para o grupo de extravasamento determina que as solicitações de serviços de clientes que não encontrem lá nenhum recurso desocupado sejam eliminadas do sistema.

Para sistemas desse tipo com apenas um grupo primário pode-se mostrar que [25]:

1. O fluxo de extravasamento que sai do grupo primário não constitui um processo de Poisson;

2. A proporção $\Pi_{c}$ de solicitações de serviços de clientes que são bloqueados no grupo secundário, em relação ao total de solicitações que extravasa do grupo primário é dada por:

$$
\Pi_{c}=\frac{a B(s+c, a)}{a B(s, a)}
$$

onde $B(s, a)$ é a fórmula Erlang $\mathrm{B}$, $a$ é a carga oferecida (em Erl) ao grupo primário, $s$ é o número de recursos do grupo primário, e $c$ é o número de recursos do grupo secundário de extravasamento.

$\mathrm{O}$ numerador de (3.11) é a média relativa à carga que extravasa do grupo secundário [25], que é denotada por $\alpha$ ' e dada por:

$$
\alpha^{\prime}=a B(s+c, a)
$$

Segue da primeira propriedade que sistemas de extravasamento geralmente não podem ser estudados por meio de métodos simples [25]. Assim sendo, utiliza- 
se (3.11) para o desenvolvimento de um método aproximado denominado método do tráfego aleatório equivalente.

\subsection{Método do tráfego aleatório equivalente}

Na Figura 3.2 estão representados dois sistemas de recursos. Consideremos o sistema esquematizado do lado esquerdo da seta. Nesse sistema, um grupo secundário de $c$ recursos atua como um grupo de extravasamento comum para todo o tráfego que extravasar dos $n$ grupos primários. Consideremos que o $i$-ésimo grupo primário consiste de $s_{i}$ recursos e que seu processo de entrada seja de Poisson, com carga oferecida de $a_{i}$ erl. Admitamos para os mecanismos de serviço de todos os grupos, que a distribuição dos tempos de serviço seja exponencial e idêntica e que esses tempos sejam independentes.
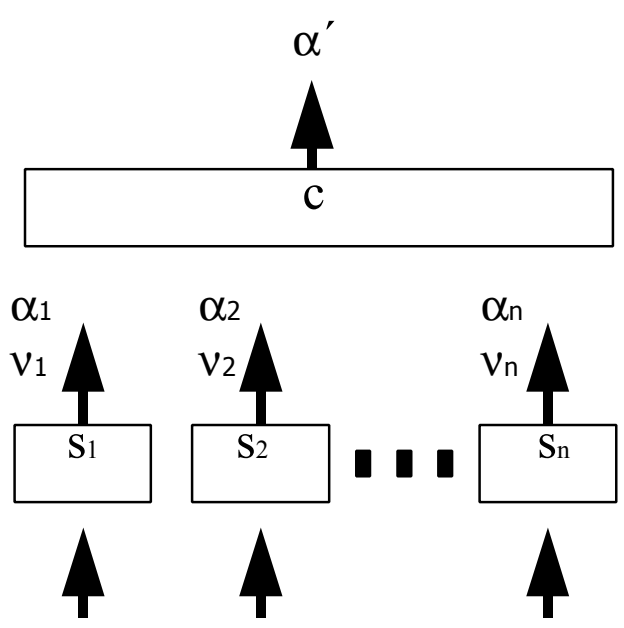

$\mathrm{a}_{1}$

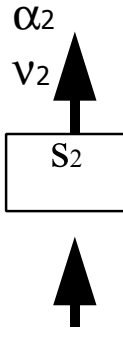

$\mathrm{a}_{2}$

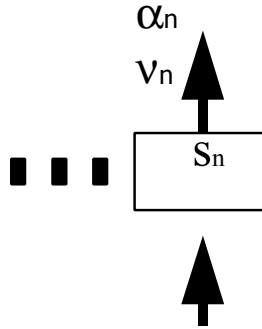

$\mathrm{a}_{\mathrm{n}}$
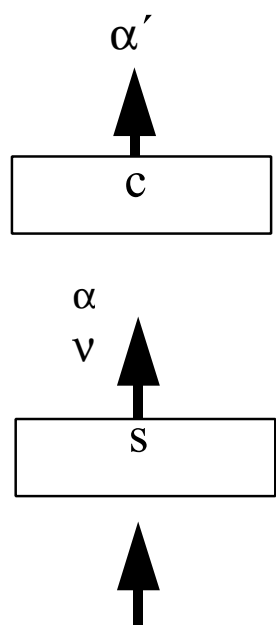

Figura 3.2. Grupos primários de recursos equivalentes [25].

Para os propósitos de uma análise aproximada, podemos representar a carga que extravasa do i-ésimo grupo primário por meio das correspondentes média $\left(\alpha_{i}\right)$ e variância $\left(v_{i}\right)$, que podem ser expressas por [25]: 


$$
\begin{array}{cl}
\alpha_{i}=a_{i} B\left(s_{i}, a_{i}\right) & (1 \leq i \leq n, i \in N) \\
v_{i}=\alpha_{i}\left(1-\alpha_{i}+\frac{a_{i}}{s_{i}+1+\alpha_{i}-a_{i}}\right) & (1 \leq i \leq n, i \in N)
\end{array}
$$

Ou seja, o fluxo de extravasamento de um grupo primário é caracterizado pela média e pela variância relativas ao fluxo de extravasamento que resultaria se o grupo secundário tivesse infinitos recursos [25].

Pretendemos inicialmente calcular a proporção de solicitações de recursos por clientes, que extravasam do grupo secundário e são eliminadas do sistema, em relação ao total de solicitações que extravasam dos $n$ grupos primários. Ou seja, calcular qual é a probabilidade de que uma solicitação que encontre todos os $s_{i}$ recursos ocupados no seu grupo primário também encontre ocupados todos os $c$ recursos do grupo secundário de extravasamento.

Uma aproximação razoável e significativa [25] pode ser dada por

$$
\frac{\alpha}{\sum_{i=1}^{n} \alpha_{i}}
$$

Como é possível calcular $\alpha_{i}$ e $v_{i}$ por meio de (3.13) e (3.14), é necessário em seguida calcular $\alpha$ '. Com essa finalidade, são substituídos os $n$ grupos primários e suas respectivas cargas por um único grupo primário equivalente e a sua respectiva carga equivalente que produzam os mesmos efeitos sobre o grupo secundário, conforme esquematizado à direita da seta na Figura 3.2. Necessita-se encontrar o número $s$ de recursos desse grupo equivalente, bem como o valor $a$ da carga equivalente que deve ser oferecida a ele, de tal forma que a média $\alpha$ e a variância $v$ da carga de extravasamento total oferecida ao grupo secundário permaneçam as mesmas.

Como os $n$ grupos primários são independentes entre si, tem-se [24],[25]: 


$$
\alpha=\sum_{i=1}^{n} \alpha_{i}
$$

e

$$
\mathrm{v}=\sum_{i=1}^{n} \mathrm{v}_{i}
$$

Os valores de $\alpha$ e $v$ podem ser substituídos em (3.9) e (3.10), gerando o sistema de duas equações e duas incógnitas $(a$ e $s)$ a seguir:

$$
\begin{gathered}
\alpha=a B(s, a) \\
v=\alpha\left(1-\alpha+\frac{a}{s+1+\alpha-a}\right)
\end{gathered}
$$

Resolvendo o sistema e determinando os valores de $a$ e $s$, pode-se substituílos em (3.11) para obter $\Pi_{c}$, que é a proporção de solicitações de serviços de clientes que são bloqueadas no grupo secundário, em relação ao total de solicitações que extravasa do grupo primário. $\mathrm{O}$ valor de $\Pi_{c}$ é tomado como a probabilidade de bloqueio no grupo secundário sofrido pelo tráfego que extravasa dos grupos primários [25].

Substituindo-se os valores encontrados de $a$ e $s$ em (3.12), obtém-se o valor de $\alpha^{\prime}=a B(s+c, a)$. Esse é o valor da carga que extravasa do grupo secundário e é eliminada do sistema [25].

Finalmente, pela expressão

$$
\Pi=\frac{\alpha}{\sum_{i=1}^{n} a_{i}}=\frac{a B(s+c, a)}{\sum_{i=1}^{n} a_{i}}
$$


se obtém a proporção $\Pi$ de todas as solicitações de recursos por clientes que são bloqueadas tanto nos grupos primários como no grupo secundário, em relação ao total de solicitações de recursos nos $n$ grupos primários. O valor de $\Pi$ é tomado como probabilidade de bloqueio no sistema de recursos primários e secundário, sofrido pelo tráfego oferecido ao sistema [25].

\subsection{Solução aproximada de Rapp}

É uma alternativa simplificada que possibilita encontrar os valores aproximados das incógnitas $a$ e $s$ do sistema das equações (3.17) e (3.18) com bastante precisão [25].

Define-se fator de granulosidade (c) por [24],[25]:

$$
c=\frac{v}{\alpha}
$$

Determinam-se $a$ e $s$ pelas equações:

$$
\begin{aligned}
& a=v+3 c(c-1) \\
& s=\frac{a(\alpha+c)}{\alpha+c-1}-\alpha-1
\end{aligned}
$$

Para se melhorar a aproximação, deve-se arredondar $s$ para a sua parte inteira $[s][25]$. Evidentemente, $[s]$ precisa também ser um número natural porque representa o número de recursos. Após o arredondamento, pode-se obter o correspondente valor de $a$ resolvendo-se (3.22) para $a$ :

$$
a=\frac{([s]+\alpha+1)(\alpha+c-1))}{\alpha+c}
$$

Os valores de $a$ e $[s]$ encontrados podem ser substituídos em (3.19) para se obter o valor de $\Pi$. 


\subsection{Fórmula de aproximação de Hayward}

A probabilidade de que chamadas que requeiram $c$ recursos de transmissão por um tempo constante $b$ em um sistema com $s$ recursos $(s>\mathrm{c})$ não encontre nenhum deles desocupado, é a mesma para chamadas com o mesmo processo de entrada, que requeiram um recurso pelo mesmo tempo constante $b$, em um sistema com capacidade $s / c$ (admitindo-se que $s / c \in N$ ). Essa probabilidade $\left(P_{B}\right)$ é dada por [24]:

$$
P_{B}=B\left(\frac{s}{c}, \frac{\alpha}{c}\right)
$$

onde $c$ é o fator de granulosidade e $\alpha$ é a variância do tráfego oferecido.

\subsection{Fórmula Erlang $C$}

Utilizou-se até aqui a seguinte disciplina de fila: quando as solicitações de serviço não encontravam recursos desocupados eram eliminados do sistema.

Nesta seção aborda-se o sistema de espera de Erlang, onde a disciplina de fila especifica que solicitações de clientes que encontrem todos os recursos ocupados ingressem em uma fila e aguardem o tempo que for necessário para serem atendidas. $\mathrm{O}$ número de posições de espera na fila é infinito. Nenhum recurso pode ficar inativo se existir alguma solicitação de cliente na fila.

Denota-se por $C(s, a)$ a probabilidade de que todos os recursos estejam ocupados. A fórmula Erlang C, também conhecida por fórmula de retardo de Erlang é expressa por [25]:

$$
C(s, a)=\frac{\frac{a^{s}}{s !\left(1-\frac{a}{s}\right)}}{\sum_{k=0}^{s-1} \frac{a^{k}}{k !}+\frac{a^{s}}{s !\left(1-\frac{a}{s}\right)}} \quad(0 \leq a<s)
$$

onde $a$ é a carga oferecida em erlangs, e $s$ é o número de recursos. 
Se o processo de entrada for um processo de Poisson, a expressão (3.25) permite obter tanto a proporção de tempo em que todos os recursos estão ocupados, como a proporção de solicitações de clientes que encontram todos os recursos ocupados [25]. 


\section{CAPÍTULO 4}

\section{MODELAGEM \\ ANALÍTICA \\ PARA \\ $\mathbf{O}$ \\ DIMENSIONAMENTO \\ DE REDE ÓPTICA \\ SEM COMUTAÇÃO}

\subsection{Introdução}

Para viabilizar o conceito da rede sem comutação é necessário pesquisar como a rede pode ser dimensionada em termos dos recursos disponíveis. Sendo assim, é necessário obter um modelo analítico que descreva o comportamento da rede.

A análise será feita considerando-se somente a existência de tráfego telefônico com o intuito de demonstrar a capacidade do sistema e de investigar os principais resultados relacionados ao seu dimensionamento. No tráfego exclusivamente telefônico, o processo de entrada é um processo de Poisson e a disciplina de fila é aquela em que chamadas que não encontrem recursos de transmissão disponíveis são eliminadas do sistema. Assim sendo, poderá ser utilizado o método do tráfego aleatório equivalente (Seção 3.8). Desse modo, poderá ser avaliada a probabilidade de bloqueio experimentada pela carga de tráfego oferecida ao sistema, em função dos recursos da rede, tais como número de PONs, número de portas reservas, número de slots de tempo, bem como do número de usuários. Assim, serão obtidos resultados significativos sobre a relação entre os parâmetros da rede. O dimensionamento da rede poderá ser feito avaliando-se quais são os parâmetros que garantem que a probabilidade de bloqueio, $P$, fique abaixo de um valor previamente fixado. Esse valor representa a escolha de um parâmetro de qualidade, como, por exemplo, $P=10^{-5}$, utilizado em [7], e que será adotado na maioria das situações a serem estudadas neste trabalho. Usando-se a fórmula Erlang $\mathrm{B}$ e o método do tráfego aleatório equivalente [24], [25], poder-se-ão equacionar os parâmetros de rede para se deduzir expressões que possibilitem atingir os objetivos propostos. 


\subsection{Definições}

A rede em estudo é constituída por um único nó central e utiliza um esquema WDMA / TDMA. A rede é organizada de tal forma que, para cada par de PONs entrada-destino existe um comprimento de onda dedicado, que contém $T$ slots de tempo destinados à conexão PON a PON. Além disso, cada PON de entrada é conectada, através de $N_{d}$ comprimentos de ondas dedicados, cada um deles também com $T$ slots de tempo, às $N_{d}$ portas reservas do PWRN, que por sua vez são conectadas às PONs de destino por meio de $N_{d}$ comprimentos de onda. Essas conexões podem ser visualizadas na Fig. 4.1.

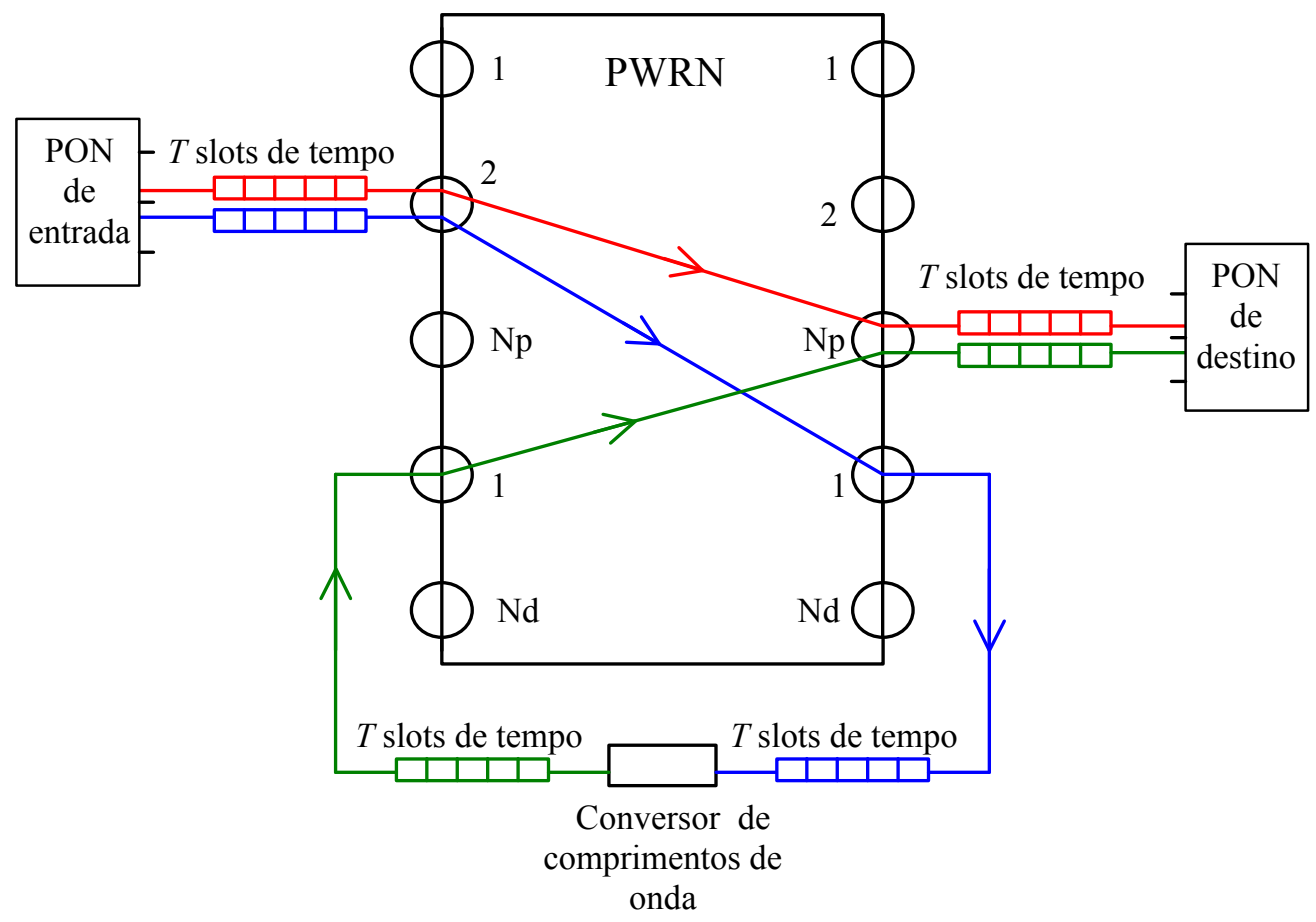

Figura 4.1. Conexões entre PONs. Um comprimento de onda dedicado à conexão direta entre duas PONs está representado em vermelho. Uma conexão entre duas PONs através de uma porta reserva utiliza uma seqüência de dois comprimentos de onda, representados em azul e verde. 
$\mathrm{Na}$ rede em estudo, o conjunto de todos os fluxos de extravasamento relativos aos comprimentos de onda que conectam diretamente uma PON de entrada com uma PON de destino, é oferecido ao sistema de portas reservas. A disciplina de fila adotada é aquela em que, chamadas que não encontrem recursos disponíveis nem nos comprimentos de onda que conectam diretamente duas PONs, nem no sistema de portas reservas, são eliminadas do sistema (bloqueadas).

Considera-se que existam $N_{p}$ PONs com $n$ clientes cada uma. O número total de usuários é:

$$
N_{\text {tot }}=n N_{p}
$$

Supõe-se que haja uma uniformidade na distribuição da carga do tráfego oferecida em relação tanto às portas de entrada como às portas de saída. Ou seja, a carga oferecida total que a rede deve atender é igualmente distribuído pelas $N_{p}$ PONs de entrada, bem como o tráfego total oferecido a cada PON de entrada é igualmente distribuído em direção às $N_{p}$ PONs de destino.

Expressões que permitam avaliar a probabilidade de bloqueio em função dos recursos da rede a serem usados e da carga oferecida devem ser obtidas. O projeto da rede necessitará dos parâmetros que garantam que a probabilidade de bloqueio seja menor que um determinado valor pré-fixado.

Será efetuada a análise do tráfego entre uma PON de entrada e uma PON de destino. Será avaliada a probabilidade de bloqueio relativa a esse tráfego, levandose em conta o efeito do tráfego associado às demais PONs. De acordo com a hipótese que pressupõe tráfego uniforme, esta probabilidade representa também a probabilidade de bloqueio associada a todo o sistema [7].

As seguintes definições expressam as variáveis em análise:

$A_{0}$ : Carga oferecida em uma PON de entrada em direção a uma única PON de destino;

$A_{0 t o t}$ : Carga oferecida em todas as PONs de entrada em direção a uma única PON de destino, ou seja, 


$$
A_{0 t o t}=N_{p} A_{0}
$$

$A_{c 1}$ : Média relativa à parte da carga oferecida que é transportada por um comprimento de onda que conecta diretamente uma PON de entrada com uma PON de destino;

$A_{0 R}$ : Média relativa ao fluxo de extravasamento de um comprimento de onda que conecta diretamente uma PON de entrada com uma determinada PON de saída (PON de destino), e que é a seguir oferecido às portas reservas;

$A_{p}$ : Somatória das médias relativas aos fluxos de extravasamento de todos os demais comprimentos de onda que conectam diretamente as outras PONs de entrada à mesma PON de destino acima referida e que são a seguir oferecidos às portas reservas. Ou seja,

$$
A_{p}=\left(N_{p}-1\right) A_{0 R}
$$

$V_{0}$ : Variância relativa ao fluxo de extravasamento de um comprimento de onda que conecta diretamente uma PON de entrada com uma determinada PON de destino, e que é a seguir oferecido às portas reservas;

$A_{c 2}$ : Média relativa à carga que é transportada através das portas reservas;

$A_{R}$ : Média relativa ao fluxo de extravasamento do sistema.

As definições anteriores estão representadas na Fig. 4.2. Para se analisar o modelo mostrado nessa figura, são admitidas as seguintes hipóteses:

1. Os comprimentos de onda que conectam as PONs fontes às portas reservas são considerados livres de bloqueio. Tal hipótese permite que se avalie a probabilidade de bloqueio relativa às portas reservas exclusivamente em função da saturação dos slots de tempo dos comprimentos de onda que conectam as portas reservas com as PONs de destino. O cálculo da probabilidade de bloqueio utilizando esta hipótese resulta em valores muito similares aos obtidos sem utilizá-las [7]. Essa hipótese é justificável, pois o comprimento de onda que conecta uma PON fonte à entrada de um 
conversor de comprimentos de onda por meio de uma porta reserva e o comprimento de onda que conecta a saída do conversor à PON de destino são dois grupos de recursos com a mesma quantidade de recursos de transmissão. Esses grupos devem ser dispostos em seqüência pelo conversor de comprimentos de onda, conforme pode ser observado na Fig. 4.1 .

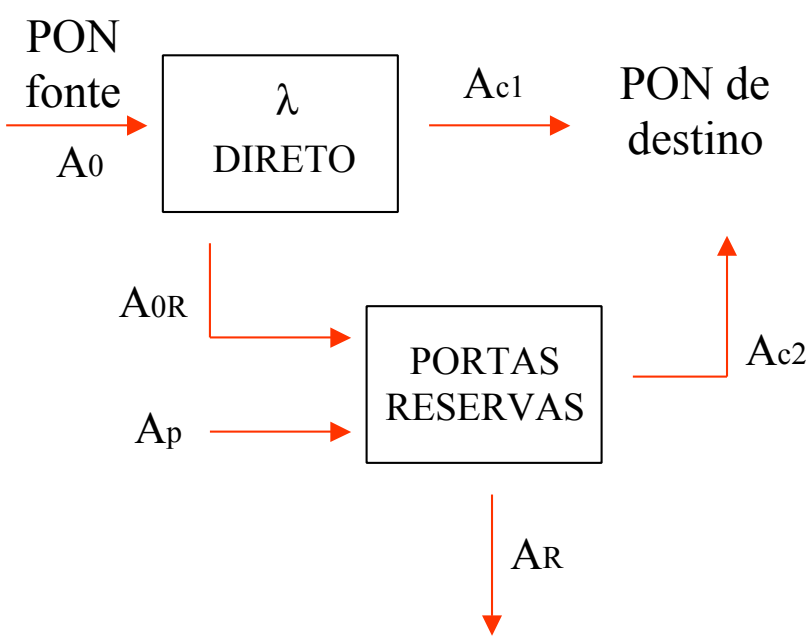

Figura 4.2. Esquema do fluxo de tráfego numa rede óptica sem comutação.

2. O tráfego que extravasa dos comprimentos de onda que conectam diretamente as PONs fontes às PONs de destino, e que é oferecido às portas reservas, é representado por meio de sua média e de sua variância.

As hipóteses anteriores permitem utilizar o método do tráfego aleatório equivalente. Cada comprimento de onda que conecta diretamente uma PON de entrada à PON de destino é considerado um grupo primário de recursos. O conjunto de comprimentos de onda que conecta as portas reservas às PONs de destino é considerado como grupo secundário de recursos.

\subsection{Cálculo da probabilidade de bloqueio no sistema de recursos primários e secundário.}

Considere uma rede óptica sem comutação da qual se conhecem $N_{p}, A_{0}, T$ e $N_{d}$. O objetivo é obter a probabilidade de bloqueio em função destes valores. 
A média relativa ao fluxo de extravasamento total $\left(A_{0 d}\right)$ oferecido ao sistema de portas reservas é dada pela soma das médias de todos os fluxos de extravasamento, de acordo com (3.15). Assim, tem-se:

$$
A_{0 d}=A_{0 R}+A_{p}
$$

Como

$$
A_{p}=\left(N_{p}-1\right) A_{0 R}
$$

Obtém-se:

$$
A_{0 d}=N_{p} A_{0 R}
$$

O fluxo de extravasamento de um comprimento de onda que conecta diretamente uma PON de entrada com a PON de destino tem sua variância $V_{0}$ calculada em função de $A_{0}, A_{0 R}$ e $T$ conforme (3.14). Assim tem-se:

$$
V_{0}=A_{0 R}\left(1-A_{0 R}+\frac{A_{0}}{T+1-A_{0}+A_{0 R}}\right)
$$

De acordo com (3.16), a variância relativa ao fluxo de extravasamento total das $N_{p}$ PONs de entrada, que é oferecido ao sistema de portas reservas, é dado por:

$$
V_{0 d}=N_{p} V_{0}
$$

Estando estabelecidas as equações acima, pode-se prosseguir com o objetivo de calcular a probabilidade de bloqueio numa rede óptica sem comutação, da qual se conhecem $N_{p}, A_{0}, T$ e $N_{d}$. O próximo passo é calcular a probabilidade, $P_{1}$, 
de que uma chamada genérica originada na i-ésima PON de entrada com direção à j-ésima PON de saída não possa ser acomodada em nenhum dos $T$ slots de tempo pertinentes ao comprimento de onda direto que as conecta.

Utilizando-se a fórmula Erlang B, (3.7), obtém-se:

$$
P_{1}=B\left(T, A_{0}\right)=\frac{\frac{A_{0}^{T}}{T !}}{\sum_{j=0}^{T} \frac{A_{0}^{j}}{j !}}
$$

Conforme (3.9), a média relativa ao fluxo de extravasamento de um comprimento de onda que conecta diretamente uma PON fonte com uma PON de destino é dada por:

$$
A_{0 R}=A_{0} P_{1}
$$

Substituindo (4.7) em (4.3), obtém-se:

$$
A_{0 d}=N_{p} A_{0} P_{1}
$$

Conhecidos os valores de $N_{p}, A_{0}$ e $T$, obtivemos $P_{1}$ por meio de (4.6). Com o valor de $P_{1}$ calculamos $A_{0 R}$ usando (4.7). Em seguida, obtivemos $A_{0 d}$ por meio da equação (4.8).

Com os valores de $A_{0}$ e $T$ e $A_{0 R}$, agora todos conhecidos, podemos então calcular $V_{0}$ por meio de (4.4). Em seguida, podemos obter $V_{0 d}$ por meio de (4.5).

Conhecidos os valores de $A_{0 d}$ e $V_{0 d}$, a próxima etapa é substituir todos os $N_{p}$ grupos primários de recursos por um único grupo primário equivalente, conforme o método do tráfego aleatório equivalente citado na Seção 3.8. Ou seja, procuram-se os valores tanto do número de recursos $N_{x}$ desse grupo equivalente, quanto da carga equivalente oferecida, $A_{x}$. Este grupo aleatoriamente equivalente será o gerador de tráfego do sistema composto pelos $N_{d}$ comprimentos de onda 
associados às portas reservas. Para esse cálculo usaremos (3.17) e (3.18), assim escritas:

$$
A_{0 d}=A_{x} \cdot B\left(N_{x}, A_{x}\right)=A_{x} \frac{\frac{A_{x}^{N_{x}}}{N_{x} !}}{\sum_{j=0}^{N_{x}} \frac{A_{x}^{j}}{j !}}
$$

e

$$
V_{0 d}=A_{0 d}\left(1-A_{0 d}+\frac{A_{x}}{N_{x}+1-A_{x}+A_{0 d}}\right)
$$

Resolvendo-se (4.10) para $A_{x}$, obtém-se:

$$
A_{x}=\left(1-\frac{A_{0 d}}{V_{0 d}+A_{0 d}^{2}}\right) N_{x}+\frac{V_{0 d}}{V_{0 d}+A_{0 d}^{2}}+A_{0 d}\left(1-\frac{1}{V_{0 d}+A_{0 d}^{2}}\right)
$$

Substituindo (4.11) em (4.9), obtém-se:

$$
\begin{gathered}
A_{0 d} N_{x} ! \sum_{j=0}^{N_{x}} \frac{\left[\left(1-\frac{A_{0 d}}{V_{0 d}+A_{0 d}^{2}}\right) N_{x}+\frac{V_{0 d}}{V_{0 d}+A_{0 d}^{2}}+A_{0 d}\left(1-\frac{1}{V_{0 d}+A_{0 d}^{2}}\right)\right]^{j}}{j !}= \\
=\left[\left(1-\frac{A_{0 d}}{V_{0 d}+A_{0 d}^{2}}\right) N_{x}+\frac{V_{0 d}}{V_{0 d}+A_{0 d}^{2}}+A_{0 d}\left(1-\frac{1}{V_{0 d}+A_{0 d}^{2}}\right)\right]^{N_{x}+1}
\end{gathered}
$$

A dedução da expressão acima está no apêndice A.

Como já são conhecidos os valores de $A_{0 d}$ e $V_{0 d}$, pode-se resolver (4.12) e obter o valor de $N_{x}$. Substituindo-se o valor encontrado em (4.11) obtemos o valor de $A_{x}$. 
O valor de $A_{R}$ é obtido por meio de (3.12), escrita sob a forma:

$$
A_{R}=A_{x} \cdot B\left(N_{x}+N_{d} T, A_{x}\right)
$$

Finalmente, a probabilidade de bloqueio de todo o sistema é calculada usando-se (3.19), escrita sob a forma:

$$
P=\frac{A_{R}}{A_{0 t o t}}
$$

Para se encontrar as soluções do sistema de equações formado por (4.9) e (4.10) sem se usar o procedimento que utiliza (4.11) e (4.12), existe a alternativa denominada solução aproximada de Rapp [25], que foi detalhado na seção (3.9). Como os valores $V_{o d}$ e $A_{0 d}$ já foram obtidos por meio de (4.5) e (4.8), respectivamente, pode-se calcular o fator de granulosidade $c$ por meio de (3.20) e se obtém

$$
c=\frac{V_{0 d}}{A_{0 d}}
$$

Substituindo-se os valores de $V_{0 d}$ e $A_{0 d}$ já conhecidos, bem como o valor de $c$ em (3.21) e (3.22), estas equações podem ser reescritas na forma

$$
\begin{gathered}
A_{x}=V_{0 d}+3 c(c-1) \\
N_{x}=\frac{A_{x}\left(A_{0 d}+c\right)}{A_{0 d}+c-1}-A_{0 d}-1
\end{gathered}
$$

As soluções encontradas por este método tem uma precisão razoável [25]. Os valores de $A_{x}$ e $N_{x}$ encontrados por meio de (4.16) e (4.17) estão geralmente acima do valor exato. Para se melhorar a aproximação, deve-se arredondar $N_{x}$ 
para sua parte inteira $\left[N_{x}\right]$. Após o arredondamento, pode-se obter o valor correspondente de $A_{x}$ resolvendo-se (4.17) para $A_{x}$ :

$$
A_{x}=\frac{\left(\left[N_{x}\right]+A_{0 d}+1\right)\left(A_{0 d}+c-1\right)}{A_{0 d}+c}
$$

O valor de $A_{x}$ obtido por meio de (4.18) e o valor de $\left[N_{x}\right]$, ainda mais próximos dos valores exatos, podem ser substituídos diretamente em (4.13), para se determinar $A_{R}$. Substituindo-se o valor encontrado de $A_{R}$ em (4.14), calculase $P$, a probabilidade de bloqueio procurada.

\subsection{Relação entre os parâmetros de um grupo primário de recursos}

Nesta seção será deduzida uma equação que relaciona o número de PONs e o número de slots de tempo que asseguram um valor pré-fixado para a probabilidade de bloqueio em cada comprimento de onda que conecta diretamente duas PONs (grupo primário de recursos).

Além das definições de $A_{0}$ e $A_{0 t o t}$ feitas na Seção 4.2, vamos definir $A_{g}$ como a carga de tráfego total oferecida ao sistema. Da definição de $A_{0 t o t}$ decorre que:

$$
A_{g}=A_{0 t o t} N_{p}
$$

De ( 4.2 ) e ( 4.19 ) decorre que:

$$
A_{g}=A_{0} N_{p} N_{p}
$$

Resolvendo-se para $A_{0}$, obtém-se: 


$$
A_{0}=\frac{A_{g}}{N_{p}^{2}}
$$

Aplicando a Fórmula de Bloqueio de Erlang, (4.6), temos:

$$
\begin{gathered}
P_{1}=B\left(T, \frac{A_{g}}{N_{p}^{2}}\right) \\
P_{1}=\frac{\left(\frac{A_{g}}{N_{p}^{2}}\right)^{T}}{\frac{T !}{\left(\frac{A_{g}}{N_{p}^{2}}\right)^{j}}} \\
\sum_{j=0}^{T} \frac{\sum_{j=0}^{T !}}{j !} A_{g}^{j-T} N_{p}^{2(T-j)}=P_{1}^{-1} \\
P_{1} \sum_{j=0}^{T} \frac{\left(\frac{A_{g}}{N_{p}^{2}}\right)^{j}}{j !}=\frac{\left(\frac{A_{g}}{N_{p}^{2}}\right)^{T}}{T !} \\
P_{1} \sum_{j=0}^{T} \frac{T !}{\frac{A_{g}{ }^{j}}{N_{p}^{2 j}}} \frac{A_{g}^{T}}{N_{p}^{2 T}}
\end{gathered}
$$

Pode-se agora utilizar (4.21) para se obter pares de valores de $T$ e $N_{p}$ capazes de assegurar a probabilidade de bloqueio especificada. 


\subsection{Aproximação de Sterling}

Quando $T$ ! atinge valores elevados, os números intermediários computados em (4.6), (4.13) e (4.21) se tornam maiores que o número limite que pode ser processado em determinados computadores. Para se contornar este problema, utiliza-se a aproximação de Sterling [24]:

$$
T ! \approx \sqrt{2 \pi} \cdot T^{T+\frac{1}{2}} \cdot e^{-T}
$$

Utilizando-se (4.22) podem ser obtidas simplificações nas equações citadas anteriormente, o que possibilita trabalhar com valores maiores de $T$ nos computadores.

\subsection{Considerações sobre o tráfego da internet}

As técnicas de tráfego desenvolvidas para redes telefônicas, baseadas na fórmula Erlang B, têm, na Internet atual, um papel secundário em seu projeto [26]. Os parâmetros de rede são geralmente baseados em regras práticas, enquanto muito esforço é gasto no projeto de uma variedade de mecanismos de qualidade de serviço (QoS). A finalidade destes mecanismos é permitir que alguns clientes privilegiados escapem dos efeitos do congestionamento, dando-lhes tratamento prioritário. Entretanto, a garantia para um cliente de classe especial de que teria qualidade pior se tivesse optado por uma classe de serviço de baixa prioridade é de valor limitado quando o nível de qualidade real pode flutuar bastante dependendo da rota de rede utilizada e de seu correspondente nível de carga de tráfego [26].

$\mathrm{Na}$ internet, quando a carga oferecida supera a capacidade do sistema de recursos de transmissão, o processamento da fila resulta em um grande aumento no número de fluxos de pacotes em curso, enquanto torna-se cada vez maior o tempo de transmissão dos mesmos. Enquanto isso, novos fluxos de pacotes continuam a chegar. Entre os efeitos do congestionamento podem estar o descarte de pacotes, que pode gerar mais tráfego se houver retransmissão, e as desistências de clientes que abandonam transferências e interrompem sessões devido à demora $[26]$. 
Para se modificar essa situação, é proposta uma disciplina de fila em que seria bloqueada a admissão de novos fluxos quando a capacidade disponível do sistema de recursos de transmissão ficasse abaixo de um determinado limiar. Seria também utilizado um roteamento adaptativo [26]. Como um processo de Poisson resulta naturalmente quando o tráfego é devido a atividades independentes de uma grande população de clientes, cada uma individualmente tendo pequena intensidade [26], poderá ser usada a teoria de tráfego de maneira semelhante a que foi utilizada para o tráfego telefônico.

A disciplina de fila da rede óptica sem comutação, e o sistema de portas reservas, que poderia ser encarado como uma espécie de roteamento adaptativo, são estruturas que poderiam permitir sua utilização pela internet, modificada conforme sugestões anteriores. Nesse caso, poderia ser estudado o dimensionamento da rede partindo-se da modelagem desenvolvida.

\subsection{Conclusão}

Neste capítulo foi elaborada a modelagem analítica das redes ópticas sem comutação, com a utilização do método do tráfego aleatório equivalente. Isto possibilita analisar e dimensionar os parâmetros de tais redes para se obter um desempenho pré-determinado. 


\section{CAPÍTULO 5}

\section{RESULTADOS DO DIMENSIONAMENTO DA REDE}

\subsection{Introdução}

$\mathrm{Na}$ pesquisa do desempenho do sistema são considerados dois cenários, correspondentes aos diferentes tamanhos da área geográfica abrangidas pela rede. São eles: a) região média, com 150.000 clientes, e b) região pequena, com 15.000 clientes. São consideradas ainda duas classes de clientes: residencial e comercial. Para clientes residenciais adota-se que a carga de tráfego oferecida por cliente é 0,05 Erl. Para comerciais, adota-se o valor de 0,15 Erl [7].

São analisados três cenários quanto à clientela: a) Totalmente residencial, ou seja, 100\% dos clientes são residenciais; b) Misto, onde parte dos clientes é residencial e parte comercial, numa proporção qualquer. São escolhidos neste estudo os valores adotados em [7], ou seja, 78\% dos clientes são residenciais e $22 \%$ são comerciais; e 3) Totalmente comercial.

É analisada a relação entre o número de PONs e o número de slots de tempo das portas do PWRN para vários cenários, considerando-se uma determinada probabilidade de bloqueio no grupo primário de recursos. Analisa-se também a probabilidade de bloqueio da rede óptica sem comutação em função do número de portas reservas e do número de PONs, e outras relações úteis para o correto dimensionamento da rede. Por meio das várias alternativas que possibilitem atingir uma probabilidade de bloqueio inferior a um determinado valor desejado, pode-se avaliar em termos de custos qual das opções é a mais vantajosa para ser projetada. 


\subsection{Relação entre o número de PONs e o número de slots de tempo nos comprimentos de onda pertinentes às portas da PWRN}

Quando estiver determinado $P_{1}$ e for conhecida a carga de tráfego total oferecida ao sistema $\left(A_{g}\right)$ pode-se estabelecer uma relação entre o número de PONs e o número de slots de tempo que atendem aos requisitos fixados. Deseja-se encontrar pares de valores de $T$ e $N_{p}$ necessários para assegurar que a probabilidade de bloqueio, $P_{1}$, experimentada em um comprimento de onda que liga diretamente duas PONs seja menor que um determinado valor. Salientamos que $P_{1}$ é a probabilidade de bloqueio apenas nos comprimentos de onda que ligam diretamente duas PONs. Nesta seção utilizaremos o valor $P_{1}=0,1$ adotado em [7], embora outros valores possam ser utilizados. Por exemplo, o indicador das metas de qualidade de serviço para a taxa de chamadas locais originadas nãocompletadas por congestionamento, da ANATEL, é 5\% [27].

Aplicando-se (4.21) obtém-se pares de valores mínimos de $T$ e $N_{p}$ que mantém a probabilidade de bloqueio dentro do especificado.

Consideremos seis valores diferentes para a carga de tráfego total oferecida ao sistema $\left(A_{g}\right)$. Partindo de $2000 \mathrm{Erl}$, que corresponde à carga oferecida por 40000 clientes residenciais, formemos uma progressão aritmética de razão 4000 Erl, cujo último termo é 22000 Erl. Com esses valores podemos obter seis relações diferentes por meio de (4.21). A Fig. 5.1 mostra os gráficos dessas relações. Para um determinado número de slots de tempo podemos obter o número de PONs correspondentes (ou vice-versa), com o auxílio da curva correspondente à carga de tráfego total oferecida correspondente.

Observa-se na Fig. 5.1 que, adicionando-se valores constantes (4000 Erl) a $A_{g}$, o espaçamento entre as curvas correspondentes diminui à medida que $A_{g}$ aumenta. Da curva para $A_{g}=2000$ Erl concluímos que para 100 slots de tempo são necessárias 5 PONs para assegurar a probabilidade de bloqueio especificada. Já para $A_{g}=22000 \mathrm{Erl}$, com 100 slots de tempo são suficientes 15 PONs para assegurar a mesma probabilidade de bloqueio. Enquanto $A_{g}$ foi multiplicada por 
um fator igual a 11 , o número de PONs só precisou ser multiplicado por 3. Isto sugere uma economia de escala para redes maiores. Por outro lado, se fixarmos o número de PONs, pode-se observar um processo semelhante, mas menos significativo, especialmente para valores correspondentes às partes das curvas que tendem a um paralelismo com o eixo horizontal.

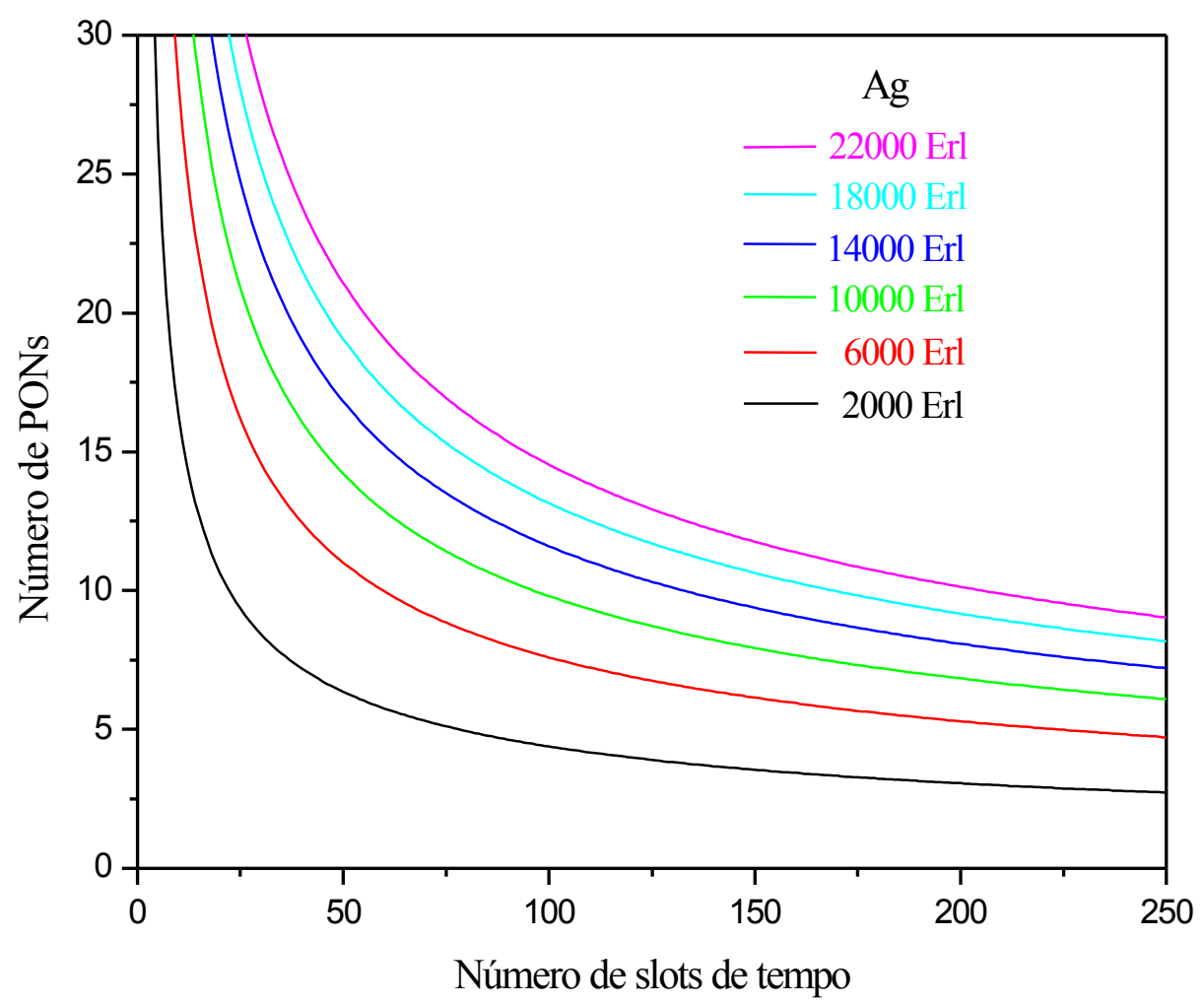

Figura 5.1. Número de PONs, $N_{p}$, versus número de slots de tempo, $T$, nos comprimentos de onda pertinentes às portas da PWRN para diversos valores de carga de tráfego oferecida ao sistema. Considerou-se $P_{1}=0,1$

Consideremos agora os cenários de tráfego mostrados na Tabela 5.1 As 6 curvas correspondentes a esses cenários são mostradas na Fig. 5.2. Observando-se a curva correspondente ao cenário $\mathrm{Cs} 1$, podem ser notadas várias alternativas de dimensionamento possíveis para $P_{1}<10^{-1}$. Se forem usados 50 slots de tempo, serão necessárias 4 PONs. Se forem usados 25 slots de tempo, haverá necessidade de 6 PONs. 
Tabela 5.1. Cenários de tráfego.

\begin{tabular}{|l|c|c|}
\hline \multicolumn{1}{|c|}{ Cenário } & Número de clientes & $\begin{array}{c}\text { Carga de } \\
\text { tráfego } \\
A_{g},(\text { Erl) }\end{array}$ \\
\hline Cs1 - Região pequena, tráfego residencial & 15000 & 750 \\
\hline Cs2 - Região pequena, tráfego misto & 15000 & 1080 \\
\hline Cs3 - Região pequena, tráfego comercial & 15000 & 2250 \\
\hline Cs4 - Região média, tráfego residencial & 150000 & 7500 \\
\hline Cs5 - Região média, tráfego misto & 150000 & 10800 \\
\hline Cs6 - Região média, tráfego comercial & 150000 & 22500 \\
\hline
\end{tabular}

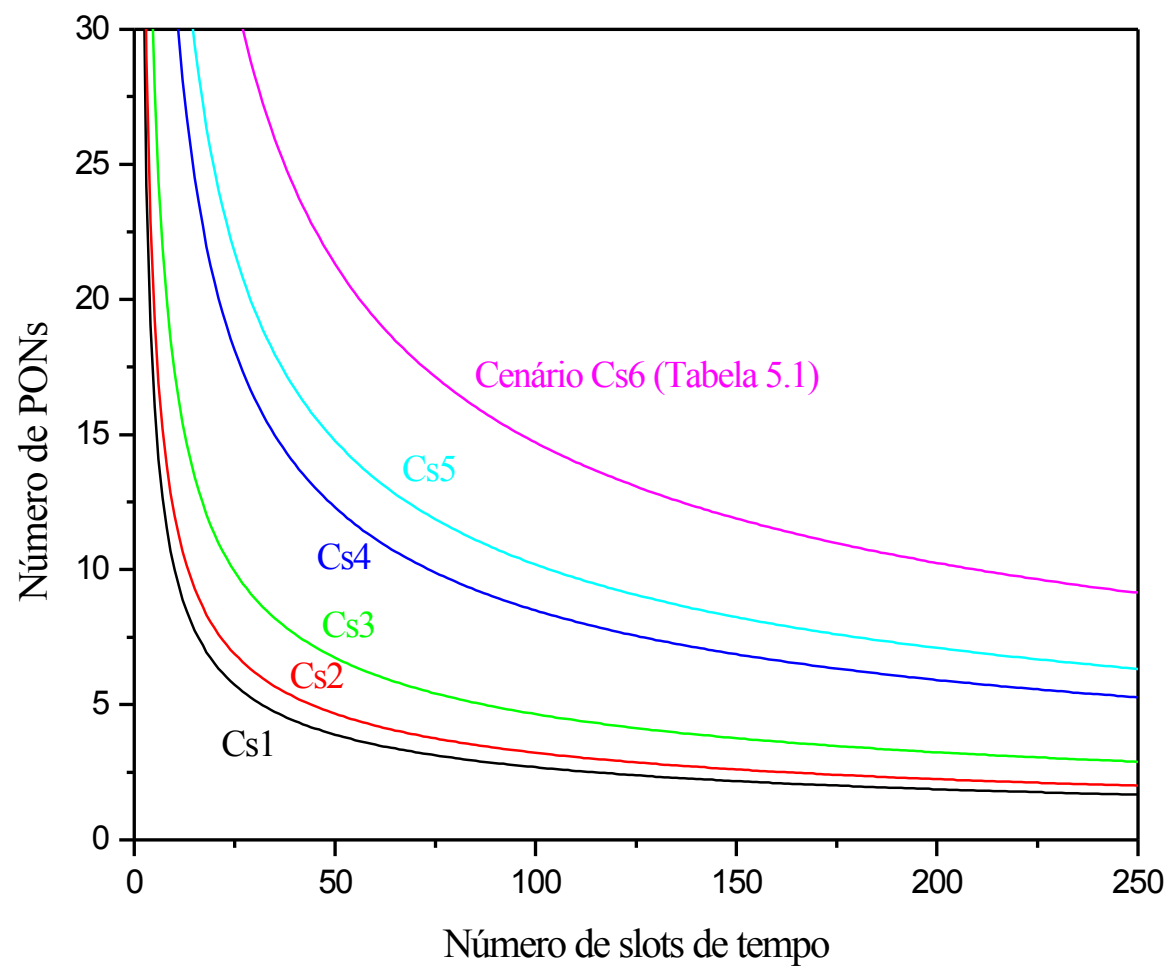

Figura 5.2. Número de PONs, $N_{p}$, versus número de slots de tempo, $T$, nos comprimentos de onda pertinentes às portas da PWRN para os cenários de tráfego Cs1 a Cs6 especificados na Tabela 5.1. Considerou-se $P_{1}=0,1$ 
Se fixarmos em 100 o número de slots de tempo, podemos obter o número de PONs necessárias em cada cenário por meio das curvas correspondentes mostradas na Fig. 5.2. A Tabela 5.2 registra os valores obtidos. Pelos resultados podemos comparar os cenários $\mathrm{Cs} 1$ e $\mathrm{Cs} 4$. Este último cenário tem o número de clientes (residenciais), e a correspondente carga de tráfego dez vezes maior que o primeiro. Pelos dados da Tabela 5.2 podemos notar que se usarmos 100 slots de tempo, serão necessárias três PONs no cenário Cs1, e nove PONs no cenário Cs4. Estas e outras comparações possíveis a partir das curvas mostradas na Fig. 5.2 permitem estabelecer o melhor dimensionamento para uma rede a ser implantada.

Tabela 5.2. Número de PONs necessárias em cada cenário. Foi fixado $T=100$.

\begin{tabular}{|c|c|}
\hline Cenário & Número de PONs necessárias \\
\hline Cs1 & 3 \\
\hline Cs2 & 4 \\
\hline Cs3 & 5 \\
\hline Cs4 & 9 \\
\hline Cs5 & 11 \\
\hline Cs6 & 15 \\
\hline
\end{tabular}

Na Fig. 5.2 as curvas relativas aos cenários Cs1 e Cs3 limitam a faixa relativa a uma região pequena. As curvas Cs4 e Cs6 limitam a faixa relativa a uma região média. Qualquer variação na proporção entre clientes residenciais e comerciais dessas regiões resultará em uma curva situada dentro da faixa correspondente.

\subsection{Cálculo da probabilidade de bloqueio de uma rede óptica sem comutação em função do número de portas reservas}

Suponhamos um sistema com $N_{p}=10, T=20$ e $A_{0}=30$. 
Se utilizarmos o processo descrito na Seção 4.3, $A_{R}$ é obtido em função de $N_{d}$ por meio de (4.13). Conseqüentemente, $P$ será obtida por meio de (4.14), também em função do número de portas reservas, $N_{d}$.

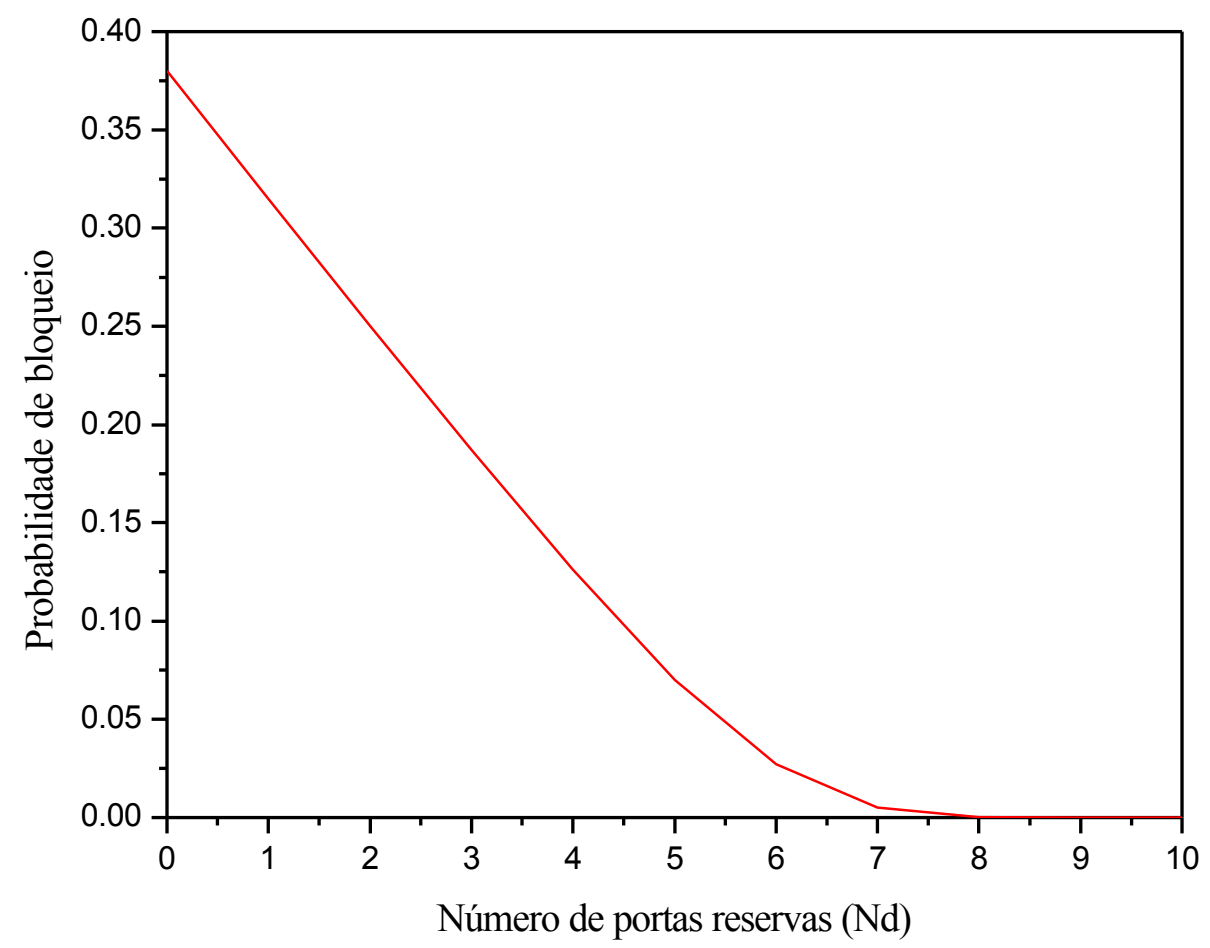

Figura 5.3. Gráfico da probabilidade de bloqueio em função do número de portas reservas. Adotados $N_{p}=10, A_{0}=30$ Erl e $T=20$.

O gráfico da probabilidade de bloqueio $P$ em função do número de portas reservas, $N_{d}$, é mostrado na Fig. 5.3.

Com base na Fig. 5.3 podemos encontrar o número de portas reservas necessárias para se obter uma probabilidade de bloqueio inferior a um determinado valor. Se for alterado o valor de $A_{0}$, pode-se observar a alteração na curva, conforme indicado na Fig. 5.4. Partindo de 30 Erl, o valor de $A_{0}$ foi variado em cinco passos de apenas 2 Erl, havendo significativas alterações nas posições das curvas relativas à probabilidade de bloqueio em função do número 
de portas reservas. Para $N_{d}=7$ a probabilidade de bloqueio para $A_{0}=40$ Erl é mais de 30 vezes maior que a probabilidade de bloqueio para $A_{0}=30$ Erl. Este tipo de gráfico pode ser utilizado para se observar a influência da variação da carga de tráfego oferecida num período de 24 horas. Conhecendo-se seus valores no horário de maior movimento (HMM) e no horário menos utilizado, pode-se obter a faixa de variação da probabilidade de bloqueio, o que permite decidir o valor de $A_{0}$ a ser utilizado no projeto.

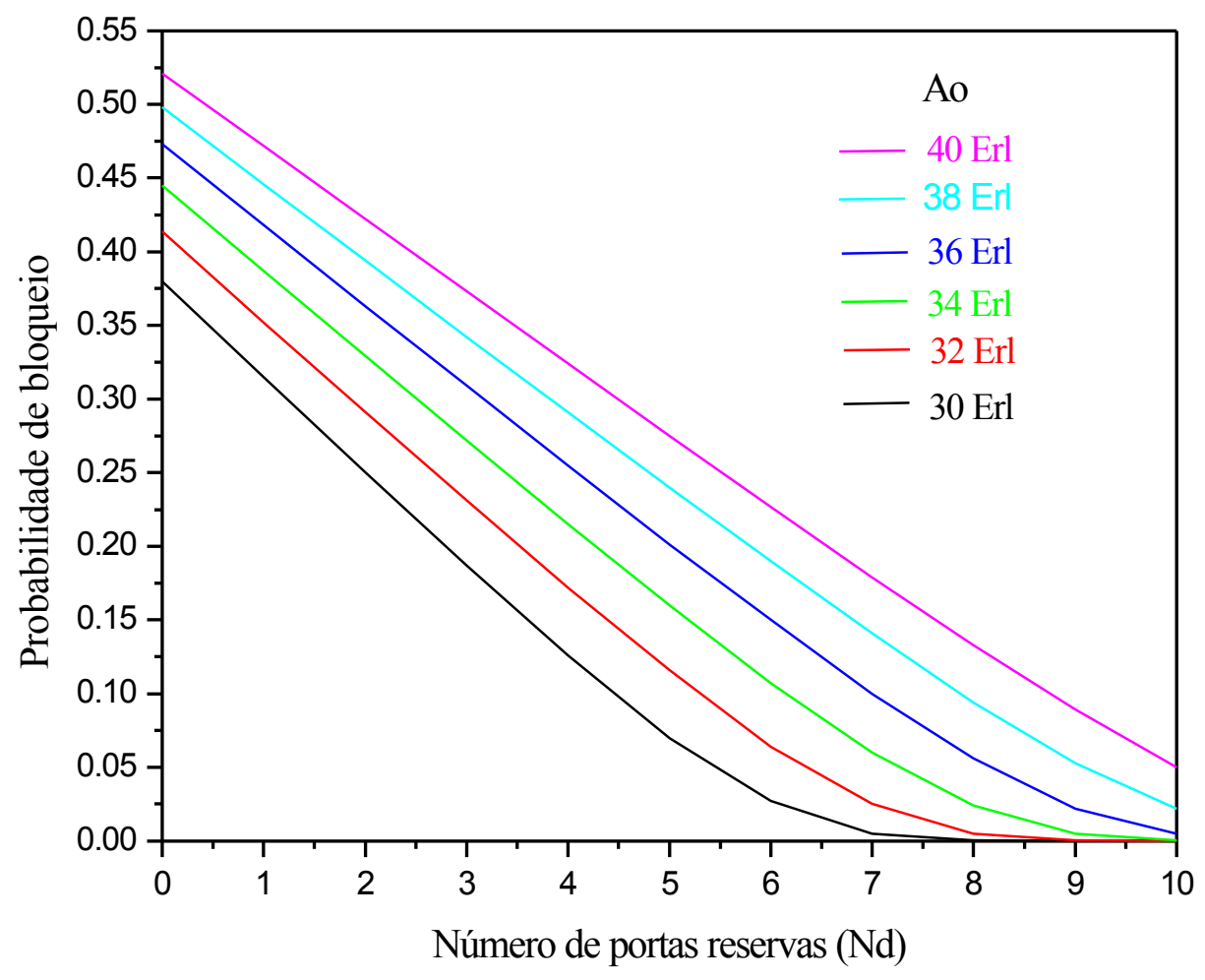

Figura 5.4. Faixa de variação da curva da probabilidade de bloqueio versus número de portas reservas, entre os limites determinados por dois valores de $A_{0}(30$ e $40 \mathrm{Erl})$. Foram adotados

$$
N_{p}=10 \text { e } T=20 .
$$




\subsection{Probabilidade de bloqueio em função do número de portas reservas e do número de PONs}

Em busca das melhores alternativas de dimensionamento da rede, pode-se estudar as variações do número de PONs, $N_{p}$, e do número de portas reservas, $N_{d}$, que atingem o mesmo objetivo.

Adotando vários valores para $N_{p}$, fixando-se a carga de tráfego total oferecida, $A_{g}$, e o número de slots de tempo, $T$, obtém-se $A_{0}$ por meio de (4.20). Em seguida, obtém-se $P_{1}$ por meio de (4.6). A seguir, obtém-se $A_{0 d}$ por meio de (4.8). Ainda, com o valor de $P_{1}$ obtém-se $A_{0 R}$ por meio de (4.7). Com os valores já conhecidos, obtém-se $V_{0}$ por meio de (4.4). Em seguida calcula-se $V_{0 d}$ por meio de (4.5).

A solução aproximada de Rapp é utilizada a seguir. Calcula-se $c$ por meio de (4.15). De posse do valor de $c$, calcula-se $A_{x}$ e $N_{x}$ usando-se (4.16), (4.17) e (4.18). Substituindo-se os valores de $A_{x}$ e $N_{x}$ obtidos em (4.13), onde $N_{d}$ é uma variável, calcula-se $A_{R}$. Finalmente, calcula-se a probabilidade de bloqueio substituindo-se $A_{R}$ em (4.14).

A Fig. 5.5 mostra os gráficos das probabilidades de bloqueio em algumas situações. Pode-se efetuar comparações com a utilização dos gráficos, visando a melhor composição de portas. Conhecendo-se a carga de tráfego oferecida (7500 Erl) e fixando-se o número de slots de tempo (50), pode-se obter a quantidade de portas reservas necessárias para se obter uma determinada probabilidade de bloqueio para cada valor de $N_{p}$ considerado $(10,11,12,13$ e 14). A partir destes resultados, podemos avaliar em termos de custos qual das opções é a mais conveniente para ser projetada.

$\mathrm{Na}$ análise da melhor opção, o número de PONs, $N_{p}$, terá um peso que envolverá não só o número correspondente de portas do PWRN, mas também a quantidade de fibras ópticas conectadas ao PWRN que se direcionam à área de atendimento. O número de amplificadores e acopladores correspondentes deverá considerado, assim como os outros componentes correlatos. Por outro lado, um número maior de PONs pode tornar mais flexível o projeto de cabos na área 
geográfica a ser atendida. Localidades separadas podem ser atendidas por uma PON exclusiva, dependendo da demanda prevista. Pode-se considerar cada PON como uma rota de expansão da rede durante a fase de implantação. Pode-se também propor que cada micro-área de manutenção coincida com uma PON, dependendo do seu tamanho. Isso facilitaria a manutenção preventiva e corretiva.

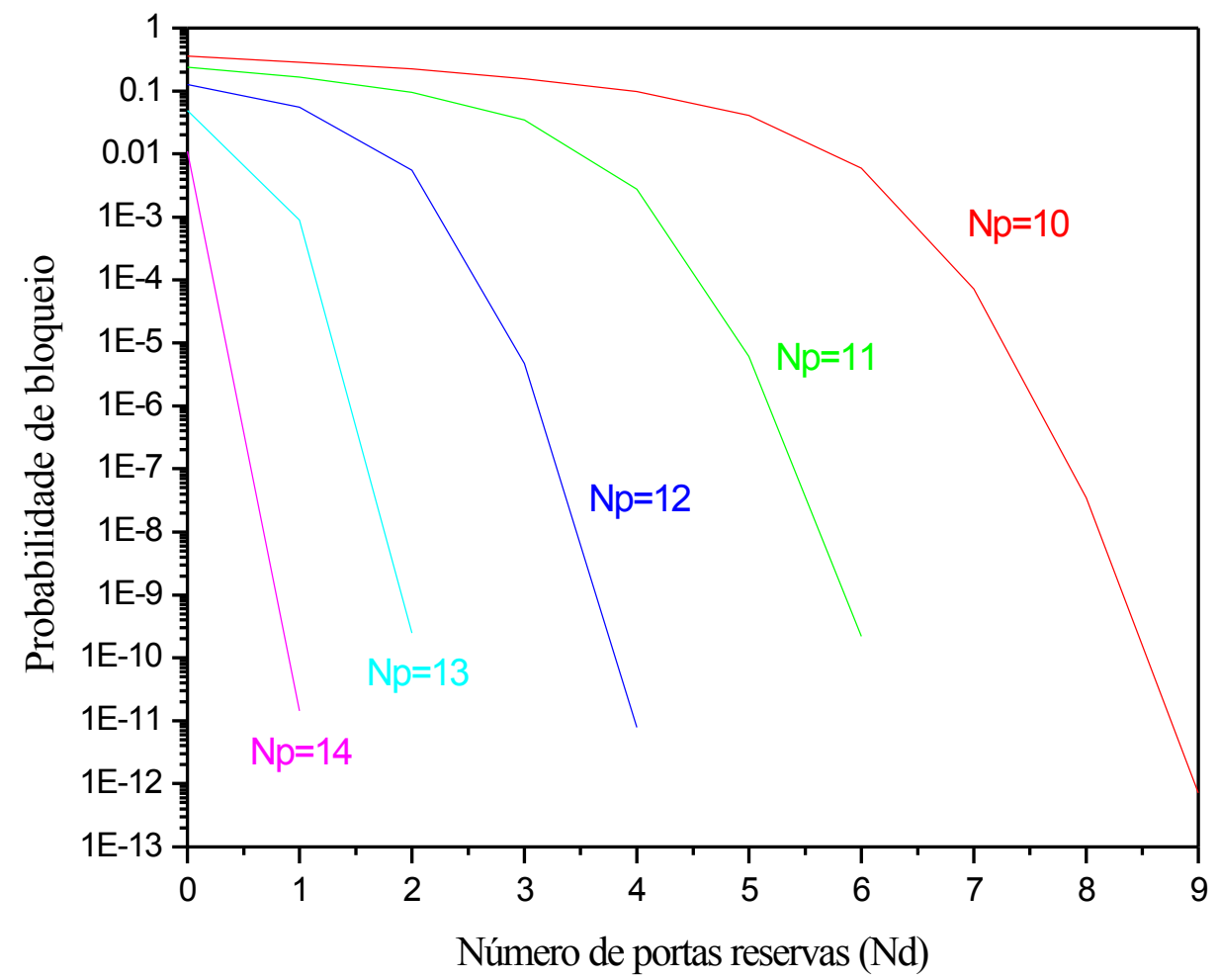

Figura 5.5. Probabilidade de bloqueio em função do número de portas reservas e do número de PONs. Considerou-se região residencial média (150000 clientes, carga oferecida de 7500 Erl). O número de slots de tempo foi fixado em 50.

Ao custo das portas reservas devem ser adicionados também os custos correspondentes às seqüências de conversores de comprimentos de onda.

Para melhor avaliar a influência do número de portas reservas e do número de PONs na implementação da rede, pode-se traçar o gráfico do número de portas 
reservas em função do número de PONs, fixando-se $A_{g}$ e $T$, conforme ilustra a Fig. 5.6, para dois valores de $P$.

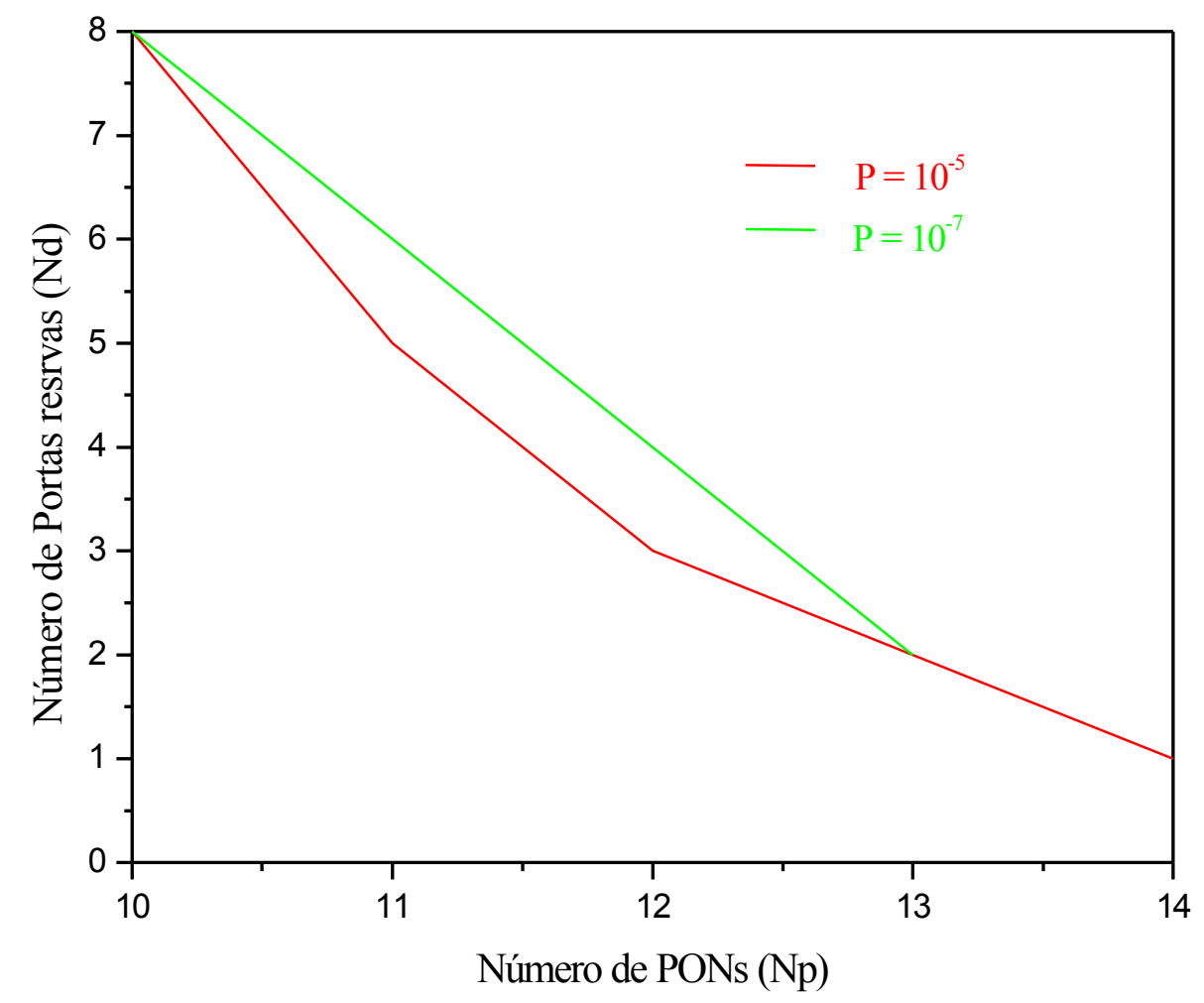

Figura 5.6. Número de portas reservas, $N d$, versus número de PONs , $N p$. Foram adotados $A g=$ 7500 Erl e $T=50$.

Foram esboçados dois gráficos, correspondentes a $P<10^{-5}$ e $P<10^{-7}$. Foram adotados $A_{g}=7500 \mathrm{Erl}$ e $T=50$. Por meio destes gráficos pode-se escolher um par de valores de $N_{d}$ e $N_{p}$ que seja mais adequado economicamente ao projeto da rede. Por exemplo, supondo-se que à cada PON esteja associada uma unidade de custo, e a cada porta reserva esteja associado um valor 1,1 vezes maior, pode-se construir uma tabela comparativa baseando-se nos gráficos da Fig. 5.6. A Tabela 5.3 mostra a comparação de custos para $P<10^{-5}$.

Pelos dados da Tabela 5.3 pode-se notar que a composição mais econômica é aquela que utiliza 1 porta reserva e 14 PONs. 
Tabela 5.3. Comparação entre pares de valores de $N_{p}$ e $N_{d}$

\begin{tabular}{|c|c|c|c|c|}
\hline$N_{d}$ & $N_{p}$ & $\begin{array}{c}\text { Custo associado às } \\
N_{d} \text { portas reservas, } \\
\text { em unidades de custo }\end{array}$ & $\begin{array}{c}\text { Custo associado às } \\
N_{p} \text { PONs, em } \\
\text { unidades de custo }\end{array}$ & $\begin{array}{c}\text { Custo total, em } \\
\text { unidades de custo }\end{array}$ \\
\hline 8 & 10 & 8,8 & 10,0 & 18,8 \\
\hline 5 & 11 & 5,5 & 11,0 & 16,5 \\
\hline 3 & 12 & 3,3 & 12,0 & 15,3 \\
\hline 2 & 13 & 2,2 & 13,0 & 15,2 \\
\hline 1 & 14 & 1,1 & 14,0 & 15,1 \\
\hline
\end{tabular}

\subsection{Probabilidade de bloqueio em função do número de slots de tempo}

Pode-se estudar a influência da variação do número de slots de tempo de cada comprimento de onda sobre a probabilidade de bloqueio de uma rede óptica sem comutação, quando é determinada a carga de tráfego oferecida e fixada a quantidade de PONs, $N_{p}$, bem como o número de portas reservas, $N_{d}$. A Fig. 5.7, que é uma contribuição ao que foi tratado em [7], mostra essa influência.

Nela são traçadas quatro curvas, cada uma delas correspondendo a um valor de $N_{p}$, conforme indicado. Para todos os casos, adotou-se que a rede óptica sem comutação atende a uma região residencial com 150000 clientes, que oferece ao sistema uma carga de tráfego total $\left(A_{g}\right)$ de 7500 Erl. Foi fixado $N_{d}=1$. Do gráfico, pode-se concluir que, para $N_{p}=13,53$ slots de tempo são suficientes para se obter uma probabilidade de bloqueio menor que $10^{-5}$.

Nos gráficos da Fig. 5.7 pode-se avaliar em conjunto a influência de três importantes variáveis $\left(N_{p}, T\right.$ e $P$ ) de uma rede óptica sem comutação. Isto permite determinar os valores apropriados para determinadas situações. 


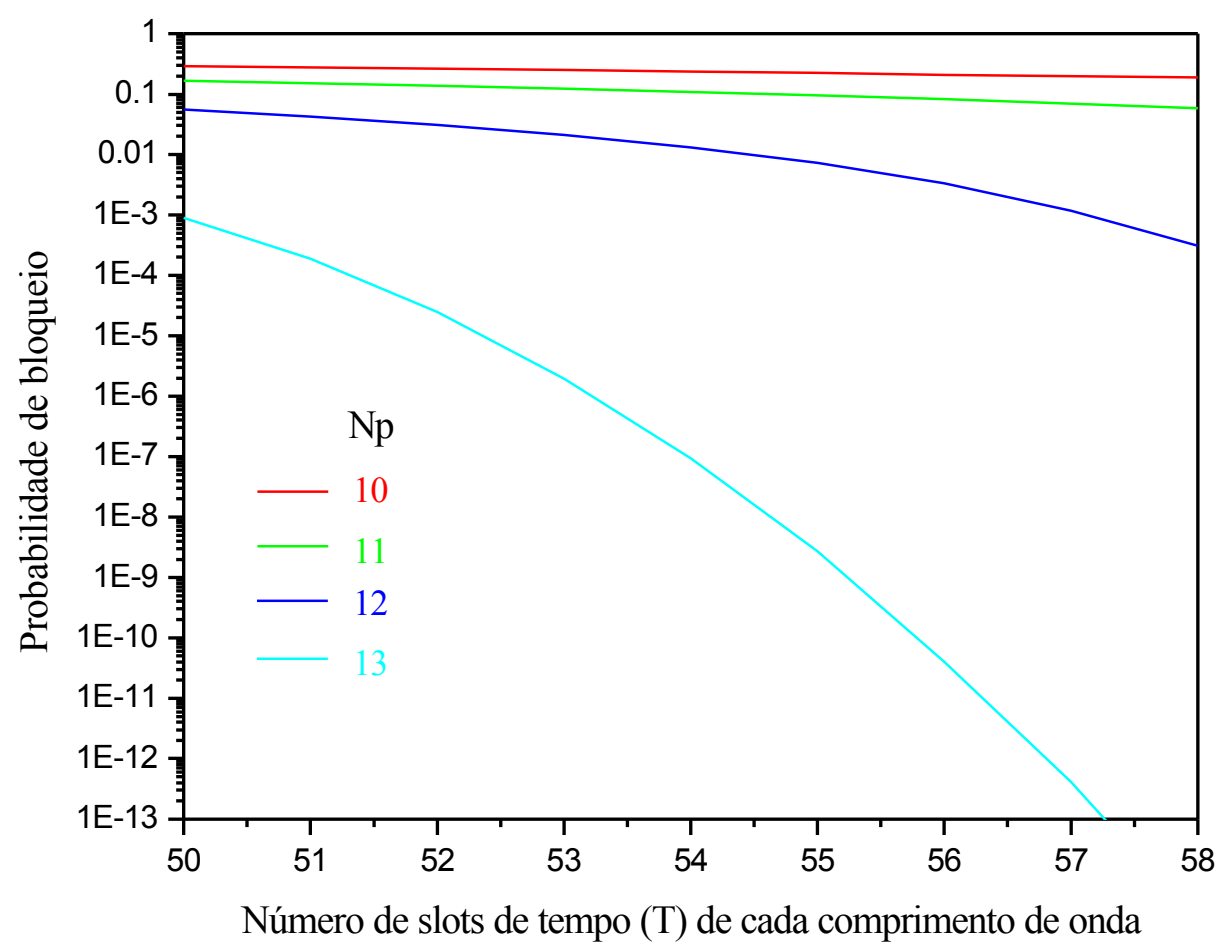

Figura 5.7. Probabilidade de bloqueio em função do número de slots de tempo de cada comprimento de onda. Foi considerada uma região residencial média com 150000 clientes (Ag $=$ 7500 Erl). Foi fixado $N d=1$.

Nota-se também nos gráficos que valores maiores de $N p$ tornam a probabilidade de bloqueio, $P$, mais susceptível à variação de $T$. Para $N p$ igual a 10 ou $11, P$ pouco varia com $T$. Na curva relativa a $N p=12$ pode-se notar que se $T$ for variado de 50 a 56, $P$ experimenta uma redução da ordem de $10^{-1}$. Já na curva relativa a $N p=13$, tal variação de $T$ provoca uma redução da ordem de $10^{-7}$.

\subsection{Número máximo de clientes que pode ser atendido por uma rede óptica sem comutação em função do número de portas reservas}

Pode-se usar a modelagem analítica desenvolvida para se determinar o número máximo de clientes que pode ser atendido por uma rede óptica sem comutação em função do número de portas reservas, $N d$, quando estiver estabelecido o limite máximo para a probabilidade de bloqueio e forem conhecidos o cenário de tráfego e o valor de $A g$ correspondente. Pode-se fixar $N p$ e obter as funções específicas para alguns valores de $T$. Os gráficos destas funções 
para 30, 31 e 32 slots de tempo estão apresentados na Fig.5.8. Supondo-se que o tráfego da região a ser atendida seja exclusivamente comercial e, partindo-se da premissa que o número de PONs foi previamente estabelecido em dez $(N p=10)$, pode-se determinar a quantidade de portas reservas necessárias para se atender a um determinado número de clientes, mantendo-se a probabilidade de bloqueio $P$ menor que $10^{-2}$. Este número foi escolhido por ser próximo ao valor atingido no Setor 31 - TELESP pelo indicador das metas de qualidade do serviço da ANATEL denominado taxa de chamadas locais originadas não completadas por congestionamento. Durante o período 01/2002 a 03/2002, o maior valor desse indicador registrado nesse setor foi de $0,98 \%$, embora a meta seja de $5 \%$ [27]. O Setor 31 é a área do Estado de São Paulo cuja concessão pertencia à Telecomunicações de São Paulo S/A até sua aquisição pela Telefonica. Não inclui a área cuja concessão era da Companhia Telefônica Borda do Campo.

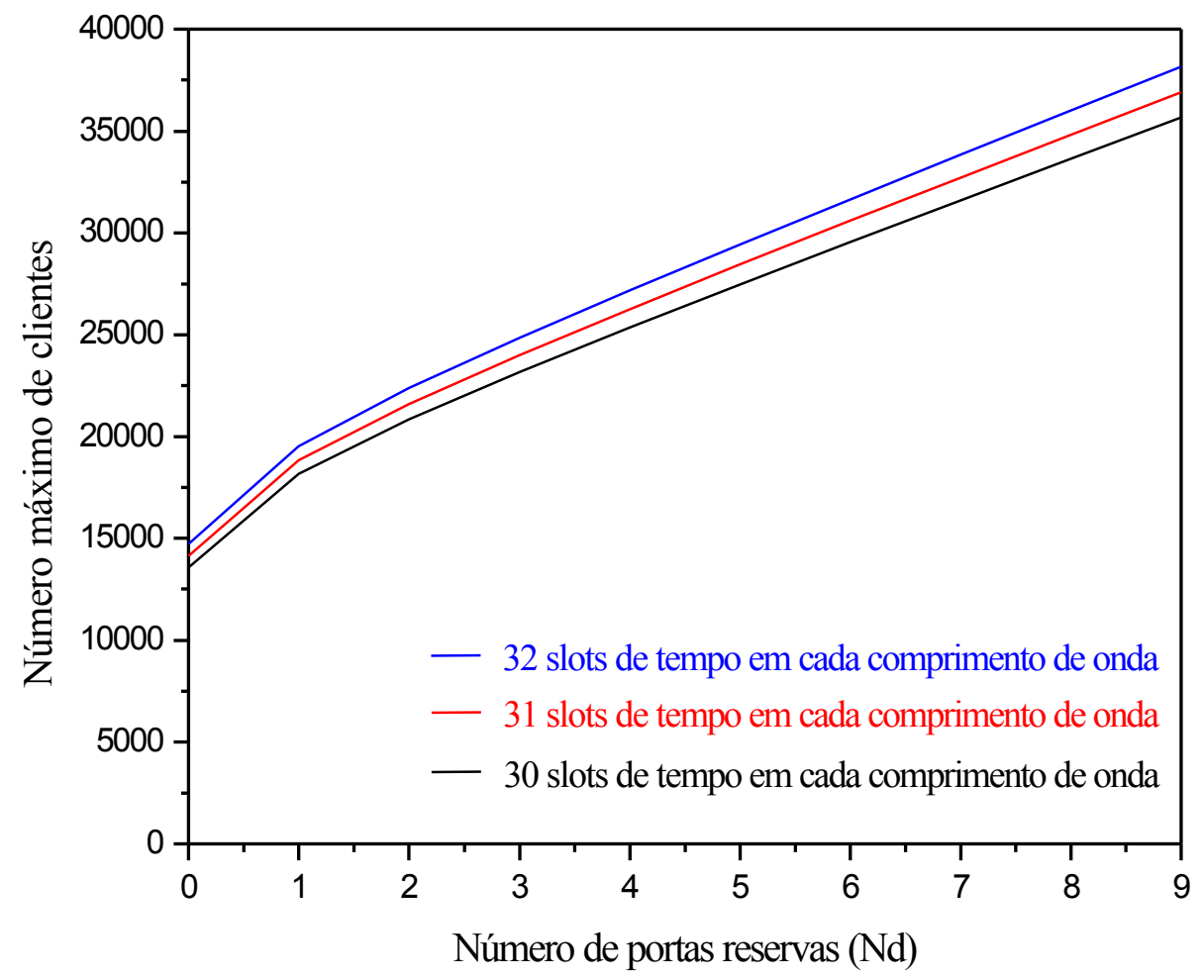

Figura 5.8. Número máximo de clientes que pode ser atendido por uma rede óptica sem comutação em função do número de portas reservas para $P<10^{-2}$. Foi considerado um cenário de tráfego em que os clientes são exclusivamente comerciais. Foi fixado $N p=10$. 
Na Fig. 5.8 pode se notar que, conforme $N_{d}$ aumenta, os formatos dos gráficos representados se aproximam do formato de gráficos de funções lineares. Consideremos a mesma região a ser atendida e o mesmo limite para a probabilidade de bloqueio. Podemos fixar $T$ e obter vários gráficos para o número máximo de clientes que pode ser atendido em função de $N_{d}$, sendo que cada um desses gráficos corresponde a um valor específico de $N_{p}$. Os resultados são apresentados na Fig. 5.9. São quatro curvas, correspondentes aos valores de $N_{p}$ variando de 10 a 14 . Na figura, pode-se notar que as curvas também tendem a retas conforme $N_{d}$ aumenta. Comparando-se as Fig. 5.8 e 5.9, nota-se que as curvas sofrem um deslocamento maior quando se altera $N_{p}$. A alteração provocada pela variação de $T$ é menos significativa.

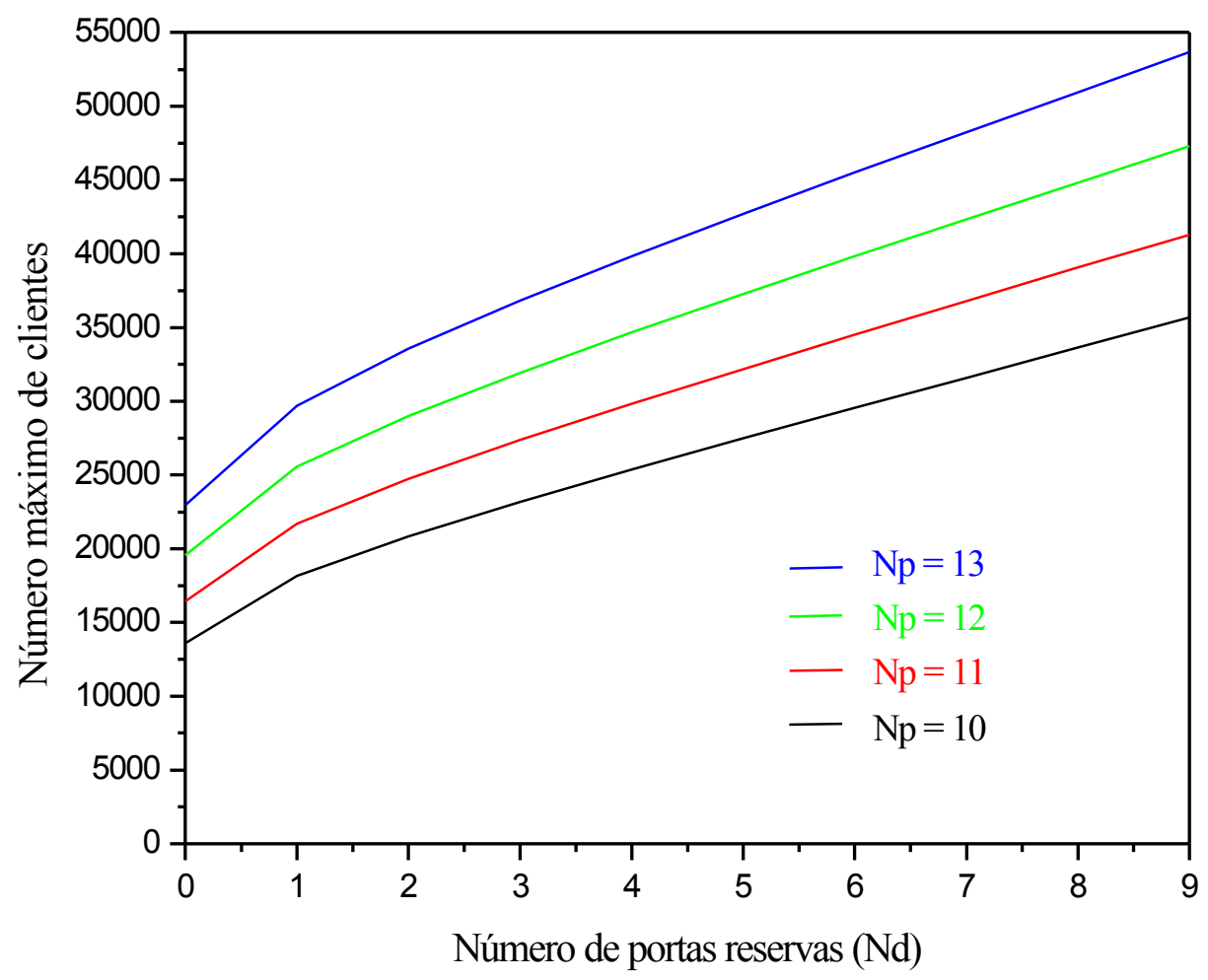

Figura 5.9. Número máximo de clientes que pode ser atendido por uma rede óptica sem comutação em função do número de portas reservas para $P<10^{-2}$. Considerou-se um cenário de tráfego em que os clientes são exclusivamente comerciais. Foi fixado $T=30$. 
Com os gráficos mostrados nas Fig. 5.8 e 5.9 pode-se estudar as melhores alternativas de projeto para uma região a ser atendida. Ou então, tratando-se de uma rede existente, pode-se determinar o número máximo de clientes que podem ser atendidos.

\subsection{Procedimentos de projeto}

A tarefa de projetar uma rede óptica sem comutação deve levar em consideração diversas variáveis. Depende inicialmente da área geográfica a ser atendida. $\mathrm{O}$ nó pode ser localizado em uma cidade maior da região e que não esteja muito fora do centro geométrico da área. É necessário pesquisar as vias de acesso mais convenientes para se projetar a colocação dos cabos ópticos. É importante verificar a existência de cabos OPGW em trajetos convenientes. Em muitas linhas de transmissão de energia elétrica no Brasil existem cabos OPGW, que podem estar com capacidade ociosa. Em trajetos convenientes, esses cabos podem ser usados para conectar várias PONS em cidades maiores. Localidades menores podem ser atendidas por uma PON exclusiva. A destinação de PONs para áreas geograficamente delimitadas, tais como cidades ou bairros, pode favorecer a divisão do serviço de manutenção em equipes distintas, bem como para a terceirização do serviço para diferentes empresas contratadas. Cada equipe ou empresa ficaria responsável pela manutenção de uma ou mais PONs específicas. Pode-se estudar também a viabilidade de se fazer coincidir uma PON com uma rede óptica existente destinada para TV a cabo.

Estando definida a área geográfica a ser atendida, pode-se calcular a carga de tráfego total oferecida ao sistema a ser projetado. Se for conhecida a variação da carga oferecida durante o período de 24 horas, pode-se utilizar gráficos semelhantes aos da Fig. 5.4 para o estudo da influência dessa variação na probabilidade de bloqueio. Isto pode ajudar na definição deste requisito fundamental (evidentemente a probabilidade de bloqueio deve ser inferior àquela exigida pelos órgãos reguladores). Os gráficos da Fig. 5.4 permitem calcular também o número de portas reservas necessárias.

Se a primeira característica da rede a ser dimensionada for o número de PONs, e se for a intenção do projetista definir o valor de $T$ desde o início, os gráficos das Fig. 5.5 e 5.6 podem ser utilizados. Na avaliação do impacto em 
conjunto de $N_{p}$ e $T$ sobre a probabilidade de bloqueio, pode-se usar gráficos semelhantes aos da Fig. 5.7. Para se calcular o número de clientes que podem ser atendidos, em função de $N_{d}$ e $T$, estando estabelecida a probabilidade de bloqueio, pode-se utilizar gráficos semelhantes aos da Fig 5.8. Da mesma forma, pode-se avaliar o número de clientes que podem ser atendidos pela rede óptica sem comutação em função de $N_{d}$ e $N_{p}$ por meio de gráficos semelhantes aos da Fig. 5.9.

Nos vários caminhos para se projetar uma rede óptica sem comutação, os resultados obtidos pelo método do tráfego aleatório equivalente podem ajudar no dimensionamento de uma rede eficiente e econômica.

\subsection{Conclusão}

Utilizando-se a modelagem analítica desenvolvida para as redes ópticas sem comutação obtida com base no método do tráfego aleatório equivalente pode-se fazer análises e comparações entre diversas situações de projeto. Isso possibilita encontrar a melhor solução entre as opções possíveis, visando menores custos, sem permitir que a probabilidade de bloqueio da rede ultrapasse valores préestabelecidos. 


\section{CAPÍTULO 6}

\section{CONCLUSÃO}

Neste trabalho foi apresentada uma modelagem que permite analisar e dimensionar redes ópticas sem comutação. Essa modelagem foi desenvolvida com base no método do tráfego aleatório equivalente, que também foi exposto. Foram apresentadas deduções de equações e obtidos gráficos que possibilitam analisar as redes sem comutação visando o dimensionamento de seus parâmetros de forma a obter as quantidades mínimas de recursos de rede que asseguram uma probabilidade de bloqueio inferior a um valor pré-especificado.

A relação obtida entre o número de PONs e o número de slots de tempo nos comprimentos de onda pertinentes às portas da PWRN permite obter pares de valores dessas variáveis que asseguram uma probabilidade de bloqueio abaixo de um valor pré-estabelecido. Essa probabilidade de bloqueio relativa aos comprimentos de onda que conectam diretamente duas PONs, que são consideradas grupos primários de recursos, poderá ser conseguida com os pares de valores que forem mais convenientes economicamente.

Por meio do cálculo da probabilidade de bloqueio de uma rede óptica sem comutação em função do número de portas reservas se obteve a possibilidade de se relacionar o número de portas reservas com a probabilidade de bloqueio para diversos valores de carga oferecida.

Fixando-se a carga de tráfego total oferecida à rede e o número de slots te tempo, obteve-se a relação entre o número de portas reservas, o número de PONs e a probabilidade de bloqueio.

Fixando-se a carga de tráfego total oferecida à rede, bem como o número de portas reservas, obteve-se a relação entre o número de PONs, o número de slots de tempo e a probabilidade de bloqueio. 
Usou-se também a modelagem analítica para se determinar o número máximo de clientes que pode ser atendido por uma rede óptica sem comutação em função do número de portas reservas, quando estiver estabelecido o limite máximo para a probabilidade de bloqueio e for conhecido o cenário de tráfego com a sua correspondente carga oferecida. Na primeira análise, fixou-se o número de PONs para se obter as três funções correspondentes a três diferentes números de slots de tempo. Na segunda análise, fixou-se o número de slots de tempo e se obteve quatro funções correspondentes a quatro diferentes números de PONs.

O conjunto de relações obtidas possibilita otimizar os parâmetros de uma rede óptica sem comutação considerando um valor máximo para a probabilidade de bloqueio. 


\section{REFERÊNCIAS BIBLIOGRÁFICAS}

[1] M. Yoo, C. Qiao e S. Dixit, "Optical burst switching for service differentiation in the next-generation optical internet", IEEE Communications Magazine, pp. 98-104, fevereiro 2001.

[2] M. Veeraraghavan, R. Karri, T. Moors, M. Karol e R. Grobler, "Architectures and protocols that enable new applications on optical networks, IEEE Communications Magazine, pp. 118-127, março 2001.

[3] M. J. O’Mahony, D. Simeonidou, D. K. Hunter e A. Tzanakaki, "The application of optical packet switching in future communications networks", IEEE Communications Magazine, pp 128-135, março 2001.

[4] D. Benjamin, R. Trudel, S. Shew e E. Kus, "Optical services over the intelligent optical network", IEEE Communications Magazine, pp 73-78, setembro 2001.

[5] A. M. Hill, S. Carter, J. Armitage, M. Shabeer, R. A. Harmon e P. Rose, “A scalable and switchless optical network structure, employing a single 32 X32 free-space grating multiplexer", IEEE Photonics Technology Letters, vol. 8, no 4 pp. 569-571, abril 1996.

[6] N. P. Caponio, A. M. Hill e R. Sabella, "Switchless optical network for advanced transport architecture", Proc. LEOS' 98, Orlando, Fl, Paper WZ4, pp. 358-359, dezembro 1998.

[7] S. Binetti, M. Listanti, A. Maga, R. Sabella, “Analysis and dimensioning of switchless networks for single-layer optical architecture", IEEE Journal of Lightwave Technology, vol. 18, $\mathrm{n}^{\mathrm{o}} 2$, pp. 144-153, fevereiro 2000. 
[8] J. C. Chen e C. Dragone, "A proposed design for ultra low-loss waveguide grating routers", IEEE Photonics Technology Letters, vol. 10, pp. 117-119, janeiro 1998.

[9] B. Glance, I. P. Kaminov e R. W. Wilson, "Applications of the integrated wave guide grating router", IEEE Journal of Lightwave Technology, vol. 12,

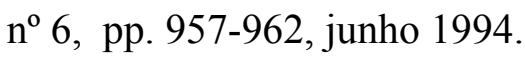

[10] D. Banerjee, J. Frank e B. Mukherjee, "Passive optical network architecture based on waveguide grating routers", IEEE Journal on Selected Areas in Communications, vol. 16, nº 7, pp. 1040-1050, setembro 1998.

[11] P. Bernasconi, C. Doerr, C. Dragone, M. Cappuzzo, E. Laskowski e A. Paunescu, “ Large NxN waveguide grating routers", Journal of Lightwave Technology, vol. 18, nº 7, pp. 985-991, julho 2000.

[12] D. Nesset, T. Elly e D. Marcenac, "All optical wavelength conversion using SOA nonlinearities", IEEE Communications Magazine, pp. 56-61, dezembro 1998.

[13] T. Durhuus, B. Mikkelsen, C. Joergensen, S. L. Danielsen, e K. E. Stubkjaer, "All optical wavelength conversion by semiconductor optical amplifiers", IEEE Journal of Lightwave Technology, vol. 14, nº 6, pp. 942954, junho 1996.

[14] T. Durhuus, B. Mikkelsen, e K. E. Stubkjaer, "Detailed dynamic model for semicondutor optical amplifiers and their crosstalk and intermodulation distortion", Journal of Lightwave Technology, vol. 10, $\mathrm{n}^{\mathrm{o}} 8$, pp. 1056-1064, agosto 1992. 
[15] C. Joergensen, T. Durhuus, C. Braagard, B. Mikkelsen, e K. E. Stubkjaer, "4 Gb/s optical wavelength conversion using semiconductor optical amplifiers", IEEE Photonics Technology Letters, vol. 5, nº 6, pp. 657-660, junho 1993.

[16] J. Leuthold, J. Eckner, C. Holtmann, R. Hess e H. Melchior, “All-optical 2x2 switches with $20 \mathrm{~dB}$ extinction ratios", Electronics Letters, vol. 32, $\mathrm{n}^{\mathrm{o}}$ 24, pp. 2235-2236, novembro 1996.

[17] N. J. Frigo, P. P. Iannone, P. D. Magill, T. E. Darcie, M. M. Downs, B. N. Desai, U. Koren, T. L. Koch, C. Dragone, H. M. Presby e G. E. Bodeep, “A wavelength-division multiplexed passive optical netwok with cost-shared components", IEEE Photonics Technology Letters, vol. $6, \mathrm{n}^{\mathrm{o}} 11$, pp. 1365-1367, novembro 1994.

[18] F. J. Effenberger, H. Ichibangase e H. Yamashita, "Advances in broadband passive optical networking technologies", IEEE Communications Magazine, pp. 118-124, dezembro 2001.

[19] S. Shimada, Coherent lightwave communications technology. Chapman \& Hall, 1995.

[20] C. K. Chan, K. L. Sherman e M. Zirngibl, "A fast 100-channel wavelengthtunable transmitter for optical packet switching", IEEE Photonics Technology Letters, vol. 13, nº 7, pp. 729-731, julho 2001.

[21] F. Tong, C. S. Li e G. Berkowitz, "A 32-channel tunable receiver module for wavelength-divison multiple-access networks", IEEE Photonics Technology Letters, vol. 9, nº 11, pp. 1523-1525, novembro 1997.

[22] S. Muroyama, M. Yamasaki, K. Takeno, N. Kato e I. Yamada, “ Design concept and characteristics of a power supply for optical network units in 
FTTH systems", IEICE Trans. Communications, vol. E81-B, $\mathrm{n}^{\circ}$ 5, maio 1998.

[23] A. S. Tanenbaun, Redes de computadores, $4^{\mathrm{a}}$ edição. Editora Campus.

[24] J. Y. Hui, Switching and traffic theory for integrated broadband networks. Kluver Academic Publishers, 1990.

[25] R. B. Cooper, Introduction to queueing theory. New York: Elsevier North Holland. Inc., 1981.

[26] J. W. Roberts, "Traffic theory and the internet", IEEE Communications Magazine, pp. 94-99, janeiro 2001.

[27] Site www.anatel.gov.br, "Plano geral de metas de qualidade (PGMQ)", janeiro a dezembro de 2002. 


\section{APÊNDICE A}

\section{DEDUÇÃO DAS EQUAÇÕES (4.11) E (4.12)}

De (4.10) obtém-se:

$$
V_{0 d}=A_{0 d}-A_{0 d}^{2}+\frac{A_{0 d} A_{x}}{N_{x}+1-A_{x}+A_{0 d}}
$$

Multiplicando-se ambos os lados da equação acima por $\left(N_{x}+1-A_{x}+A_{0 d}\right)$ e reunindo-se os termos semelhantes, obtém-se:

$$
\begin{gathered}
V_{0 d} N_{x}+V_{0 d}-V_{0 d} A_{x}+V_{0 d} A_{0 d}=A_{0 d} N_{x}+A_{0 d}-A_{0 d}^{2} N_{x}+A_{0 d}^{2} A_{x}-A_{0 d}^{3} \\
-V_{0 d} A_{x}-A_{0 d}^{2} A_{x}=-V_{0 d} N_{x}+A_{0 d} N_{x}-A_{0 d}^{2} N_{x}-V_{0 d}-V_{0 d} A_{0 d}+A_{0 d}-A_{0 d}^{3}
\end{gathered}
$$

Resolvendo-se para $A_{x}$, obtém-se:

$$
\begin{aligned}
& A_{x}=\frac{-V_{0 d}+A_{0 d}-A_{0 d}^{2}}{-V_{0 d}-A_{0 d}^{2}} N_{x}+\frac{-V_{0 d}-V_{0 d} A_{0 d}+A_{0 d}-A_{0 d}^{3}}{-V_{0 d}-A_{0 d}^{2}} \\
& A_{x}=\left(1+\frac{A_{0 d}}{-V_{0 d}-A_{0 d}^{2}}\right) N_{x}+\frac{-V_{0 d}+A_{0 d}\left(-V_{0 d}+1-A_{0 d}^{2}\right)}{-V_{0 d}-A_{0 d}^{2}}
\end{aligned}
$$

Segue-se então a expressão

$$
A_{x}=\left(1-\frac{A_{0 d}}{V_{0 d}+A_{0 d}^{2}}\right) N_{x}+\frac{V_{0 d}}{V_{0 d}+A_{0 d}^{2}}+A_{0 d}\left(1-\frac{1}{V_{0 d}+A_{0 d}^{2}}\right)
$$


que é a equação (4.11).

Em (4.9), substituindo-se $A_{x}$ pela expressão obtida no lado direito de (4.11), obtém-se:

$$
A_{0 d}=\frac{\left[\left(1-\frac{A_{0 d}}{V_{0 d}+A_{0 d}^{2}}\right) N_{x}+\frac{V_{0 d}}{V_{0 d}+A_{0 d}^{2}}+A_{0 d}\left(1-\frac{1}{V_{o d}+A_{0 d}^{2}}\right)\right]^{N_{x}+1}}{N_{x} ! \sum_{j=0}^{N_{x}}\left[\left(1-\frac{A_{0 d}}{V_{0 d}+A_{0 d}^{2}}\right) N_{x}+\frac{V_{0 d}}{V_{0 d}+A_{0 d}^{2}}+A_{0 d}\left(1-\frac{1}{V_{0 d}+A_{0 d}^{2}}\right)\right]^{j}}
$$

Finalmente, obtém-se,

$$
\begin{gathered}
A_{0 d} N_{x} ! \sum_{j=0}^{N_{x}} \frac{\left[\left(1-\frac{A_{0 d}}{V_{0 d}+A_{0 d}^{2}}\right) N_{x}+\frac{V_{0 d}}{V_{0 d}+A_{0 d}^{2}}+A_{0 d}\left(1-\frac{1}{V_{0 d}+A_{0 d}^{2}}\right)\right]^{j}}{j !}= \\
=\left[\left(1-\frac{A_{0 d}}{V_{0 d}+A_{0 d}^{2}}\right) N_{x}+\frac{V_{0 d}}{V_{0 d}+A_{0 d}^{2}}+A_{0 d}\left(1-\frac{1}{V_{0 d}+A_{0 d}^{2}}\right)\right]^{N_{x}+1}
\end{gathered}
$$

que é a equação (4.12). 